\title{
From passing-gesture to 'true' romance: Kin-based teasing in Murriny Patha conversation
}

\author{
Joe Blythe* \\ Language and Cognition Group, Human Sociality and Systems of Language Use, Max Planck Institute for Psycholinguistics, P.O. Box 310, 6500 AH Nijmegen, \\ The Netherlands
}

\section{A R T I C L E I N F O}

\section{Article history:}

Received 16 February 2011

Received in revised form 7 October 2011

Accepted 24 November 2011

\section{Keywords:}

Teasing

Kinship

Australian Aboriginal interaction

Pragmatic inversion

Deadpan jocular irony

\begin{abstract}
A B S T R A C T
Just as interlocutors can manipulate physical objects for performing certain types of social action, they can also perform different social actions by manipulating symbolic objects. A kinship system can be thought of as an abstract collection of lexical mappings and associated cultural conventions. It is a sort of cognitive object that can be readily manipulated for special purposes. For example, the relationship between pairs of individuals can be momentarily reconstrued in constructing jokes or teases.

Murriny Patha speakers associate certain parts of the body with particular classes of kin. When a group of Murriny Patha women witness a cultural outsider performing a forearm-holding gesture that is characteristically associated with brothers-in-law, they re-associate the gesture to the husband-wife relationship, thus setting up an extended teasing episode. Many of these teases call on gestural resources. Although the teasing is at times repetitive, and the episode is only thinly populated with the telltale "off-record" markers that characterize teasing proposals as non-serious, the proposal is sufficiently farfetched as to ensure that the teases come off as more bonding than biting.
\end{abstract}

(C) 2011 Elsevier B.V. All rights reserved.

\section{Introduction}

The mechanics of teasing in conversation are generally not well understood because teases have received only limited attention in studies of social interaction. Teasing in Australian Aboriginal conversation is even less well understood because the detailed study of face-to-face interaction in Aboriginal communities is still in its infancy. This paper takes a multimodal examination of an extended teasing episode from Aboriginal talk-in-interaction conducted in the Murriny Patha language of Wadeye in the Northern Territory of Australia. The teasing episode is triggered by a well-intentioned and respectful forearmholding gesture that has culturally specific associations pertaining to a particular class of kin. Having witnessed the gesture in question, the teasers re-associate the gesture to a somewhat different class of kin and then apply the relevant relationships to the individuals in question so as to affect a highly contextual and culturally specific type of tease.

The person that prompts the teasing episode interacts with the conversationalists so briefly he is little more than a passerby. Being a white man that they didn't know, from a kinship perspective, he is an 'outsider' (non-kin). Nevertheless, the participants in this conversation readily incorporate him into their kinship system (momentarily) in order to tease one of their own. The episode makes for an unusual case study as it draws on kin-denoting gestural resources and cross-cultural (miss)-communication as a trigger for the teasing.

The attested phenomenon is a playful rearrangement of the kinship system that draws on understood associations between particular categories of kin and parts of the body. Whilst kin-based teasing has been reported in the Anthropological literature,

\footnotetext{
* Tel.: +31 243521566; fax: +31 243521213; mobile: +31 633628101.

E-mail addresses: joe.blythe@mpi.nl, blythe.joe@gmail.com.
} 


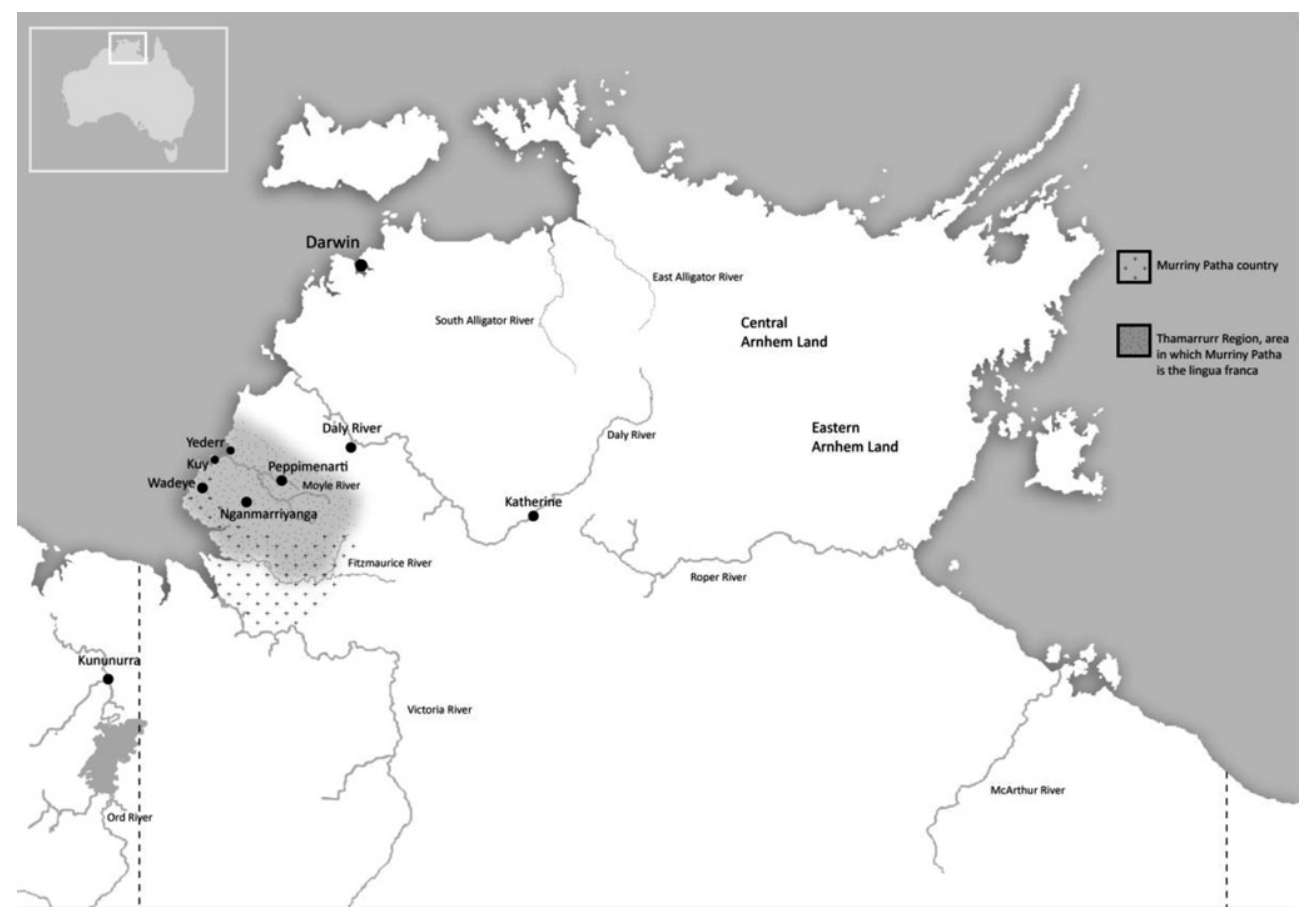

Map 1. The Murriny Patha language can be heard in the indicated towns and communities. Wadeye is the largest community in the Thamarrurr region, which is where Murriny Patha is the regional lingua franca.

its instantiation in face-to-face conversation has received very limited attention in studies of social interaction. One exception, Garde (1996, 2008) examines kin-based teasing from Central Arnhem Land (Northern Territory of Australia) between affinal 'joking' partners - that is, classificatory affines that are unlikely to ever become actual affines. ${ }^{1}$ This often ribald teasing pragmatically inverts the highly circumspect behaviours characteristic of actual affines in avoidance relationships. Garde suggests this inversion is a pragmatic index of the absence of actual affinity and the circumspection that such relationships demand. The episode considered in this paper differs slightly in that the teasing is not between persons in a formal joking relationship but, as with the formal joking relationships, the teasing does index a potential marriage that is unlikely to ever transpire.

This author is one of a small yet growing band of researchers using conversation analytic methods to study interaction in Australian Aboriginal communities ${ }^{2}$ and, more generally, in non-industrialised societies. The findings presented here are part of ongoing research into the Murriny Patha language and into the social interaction of ethnic Murriny Patha, Marri Ngarr, Marri Tjevin, Marri Amu and Magati Ke peoples, all of who speak Murriny Patha natively on a daily basis. Murriny Patha is an indigenous lingua franca spoken by some 2500 speakers of all ages, mainly in Wadeye and the smaller communities surrounding it (see Map 1). It is a morphologically complex language of the polysynthetic type. It is syntactically head-marking with free word order. Although certainly an endangered language, by Australian standards it is relatively vital, being spoken by all Aboriginal residents of Wadeye, of every generation. This makes Wadeye an optimum location for researching indigenous language use in social interaction.

Although the teasing in this paper draws on culturally specific resources pertaining to the speakers of Murriny Patha, there are broader interactional lessons to be learnt about what sorts of teases are likely to solicit serious or non-serious responses from recipients. When the relationship between individuals becomes the subject of a tease, if the relationship is portrayed favourably, then the teasing can promote affiliation between conversationalists. Furthermore, as well as features of the teasing turn design, both the poignancy of the teasing attribution and the degree of farcicality of the teasing proposal seem to have a bearing on how teases will be received.

\section{Teasing, joking and bullying}

Teases are humorous social actions that are associated with laughter and play, as well as with flirtation, bonding and bullying; even with conflict resolution. Whilst many researchers broadly conceive of teases as "mocking but playful jibes against someone" (Drew, 1987:219), teasing has often been subsumed under broader notions such as interactional humour

\footnotetext{
${ }^{1}$ Affines are relatives by marriage (in-laws). Classificatory affines are potential in-laws (fathers, mothers, siblings, etc., of a potential spouse).

2 For recent contributions within this sphere see the special edition of Australian Journal of Linguistics on Aboriginal interaction (Gardner and Mushin, 2010).
} 
or conversational joking (e.g., Glenn, 2003; Norrick, 2003), leaving teases under-differentiated from other types of humorous behaviour (cf. Keltner et al., 2001). Recognising this, other scholars consider teasing to be a sufficiently heterogeneous group of activities as to restrict their treatment of teasing to specific interactional settings, or to teasing delivered in a particular style, such as jocular mockery (e.g., Haugh, 2010).

Teasing has been a topic of inquiry for researchers from a range of disciplines (conversation analysis, interactional sociolinguistics, discursive psychology, social anthropology and experimental psychology), who have drawn on such methods as observational studies of natural interaction, interviews and questionnaires, ethnographic fieldwork and laboratory experiments. (See Keltner et al. (2001) for an empirical review.)

Teasing has been examined within adult conversations (Alberts, 1992; Drew, 1987; Haugh, 2010; Spielmann, 1998; Straehle, 1993), amongst children within primary schools (Lytra, 2007; Thorne, 1993; Voss, 1997) and high schools (Hoover et al., 1992; Moore, 1992), within child-directed speech (Demuth, 1986; Haviland, 1986; Miller, 1986; Schieffelin, 1986), within fraternity and sorority houses (Keltner et al., 1998; Lyman, 1987), within the workplace (Geyer, 2010; Handelman and Kapferer, 1972; Pizzini, 1991; Schnurr, 2009), within multicultural/multiethnic settings (Lytra, 2007, 2010), and with autistic children (Heerey et al., 2005). Most researchers recognise important pro-social functions of teasing such as affiliation, rapport building and various socialization practices springing from teasers' highlighting deviant behaviour. Others, especially those investigating teasing amongst children (Boulton and Hawker, 1997; Olweus, 1978, 1993) have highlighted the antisocial functions of teasing and have tended to conflate teasing with bullying.

Although both joking and bullying behaviours may employ teases, there are certain interactional constraints that make teases particular sorts of practices. Boxer and Cortés-Conde regard teasing as requiring the joking be directed at a person present in the interaction (as either addressed or non-addressed recipient), such that the person "becomes the centre of an interaction in which a humorous frame has been set up" (1997:279). Keltner et al. (2001:229) define teasing as "an intentional provocation accompanied by playful markers that together comment on something of relevance to the target of the tease". This definition, which includes both pro-social and antisocial dimensions of teasing, allows the phenomenon to be differentiated from related interactional practices.

Teases are complex actions that have simultaneously hostile and friendly components. According to Boxer and Cortés-Conde (1997:276) the degree of playfulness vs. provocation lies on "a continuum that ranges from bonding to nipping to biting". Because of this double-edge, teasing is said to be simultaneously face threatening (antagonistic or provocative) and face supporting (showing friendliness, promoting solidarity), both to the teaser and to the target of the tease (Keltner et al., 2001). Other politeness theorists influenced by conversation analysis claim that rather than considering face-threats and face-support as pertaining to individual participants, teases are more usefully examined from the perspective of how facework operates on the relationships between individuals, particularly on how these relationships evolve (Geyer, 2010; Haugh, 2010).

Kinship-based teasing has mostly been associated with ritualised joking relationships (Radcliffe-Brown, 1940; Thompson, 1935) in which mockery and insults between joking partners are not only sanctioned but are more or less obligatory. Much of this research has been based on African societies (e.g., Freedman, 1977; Radcliffe-Brown, 1940, 1949, 1952; Rigby, 1968). Within Australia the joking/swearing relationships have been examined in Cape York (Jackes, 1969; Thompson, 1935) and Central Arnhem Land (Garde, 1996, 2008). They have in general received less linguistic attention than the very constrained language of avoidance relationships (e.g., Dixon, 1972; Harris, 1970; Haviland, 1979; McGregor, 1989; Rumsey, 1982). Garde (2008), however, points out that extreme joking/swearing behaviour is characteristically performed by the same classes of affinal kin as those that observe strict avoidance (and thus display constrained behaviours). The joking partners are those classificatory affines for whom there is little prospect of becoming actual affines (i.e., because no marriageable relatives are available to be promised to the joking partner).

The stylistic features of the joking speech and the behavioural characteristics of the joking/swearing partners are the polar opposites of those that characterisize the highly constrained avoidance styles. According to Garde (2008:237):

The principle illustrated in the Arnhem Land cases [...] is that speakers in joking relationships use the inversion of constrained behaviours to index pragmatically the absence of actual affinity. The humour created by such inversion serves to ratify relationships between classificatory affines who are usually not expected to become actual affines.

There is a tension caused by the ambivalent status of such classificatory affinal relationships. On the one hand, the kinsman has a sort of 'obligation' to provide a spouse. On the other hand, because no suitable spouse is available, the obligation cannot be fulfilled. One style of joking, the 'mock refusal' draws on this tension by making light of this unfulfillable obligation (e.g., Fragment 1, Garde, 2008:239).

Fragment 1 (Bininj Gunwok language)

A: Kan-berrebbu daluk

Promise me a wife.

B: Larrk kaybun

No, I'll refuse you.

((both laugh))

The locus classicus from the conversation analysis tradition is Drew's (1987) study of teasing in British and American conversations. Drew shows that even though recipients recognise teases as being humorous offerings, the majority of teases 
are nonetheless met with po-faced (serious) responses. Drew shows that from an interactional perspective, teases are usually 'seconds' that are responsive to prior turns at talk. Furthermore, the teased person is usually the producer of the turn to which the tease is responsive. The initial turns frequently contain "minor conversational transgressions" (Drew, 1987:219) such as overdone complaints, extollings and boasts, etc. As such, the teasing turns tend to highlight the particular behaviour in the prior turn that is overdone. Drew shows that in the majority of cases, even when recipients of a tease laugh, and even if they play along with the teasing proposal, recipients of a tease will more often than not reject the proposal and try to "set the record straight" (Drew, 1987:230).

The jocular frame tends to be revealed through constellations of various design features (or "off-record markers”, Keltner et al., 2001:235-236) that show that the teasing proposal is to be taken as non-serious. Teases are marked as jocular though facial displays such as smiles, laughter particles produced on completion of the tease (Glenn, 2003; Jefferson, 1979), mock acts of aggression (Lytra, 2007, 2010; Miller, 1986), nickname usage (Lytra, 2007, 2010), marked pronoun usage (Straehle, 1993), formulaic expressions such as Yes, dear (Straehle, 1993), and exaggerated lexical selection (e.g., extreme case formulations such as all, always, the most, the best, every, never) (Edwards, 2000; Pomerantz, 1986). Prosodic exaggeration can be cued by vowel lengthening, singsong intonation and by shifts in amplitude and register (Haugh, 2010; Keltner et al., 2001; Lytra, 2007; Miller, 1986; Straehle, 1993). On the other hand, deadpan jocular irony (Goddard, 2006) (sometimes employed in teasing) can be cued by pitch range compression (Attardo et al., 2003; Haugh, 2010). Because teases are typically designed as exaggerated or gross versions of actions/categories depicted in the prior turns (Drew, 1987), lexical and prosodic exaggeration are pointed tools for highlighting the conversational transgressions that actually prompt the teases. Keltner et al. (2001) suggest that the more off-record markers are included in the teasing sequence, the more likely the teasing proposal will be perceived as jocular. By contrast, if the off-record markers are few in number, the more likely the proposal will be perceived as serious, and the tease as being hostile in flavour.

Drew's membership category analysis provides certain insights into why recipients of teases tend to reject teasing proposals:

In the tease, an abnormal or somehow deviant category or activity is attributed to the recipient (or [...] to the subject of the tease). For that deviant attribution to conceivably apply, it minimally requires some category or activity should apply to the recipient/subject of the tease. Inasmuch as this minimally required normal activity or category actually does apply to them, recipients can see themselves as conceivably portrayed in the tease. (Drew, 1987:246)

Thus, in Drew's (1987) examples, a man extolled as being attractive to women in an initial telling is in the tease ascribed the deviant property of being sexually manipulative, friends initially portrayed as innocently talking to each other are deviantly presented as gossiping or endlessly yacking, and a student who initially brags about getting good results in a test is deviantly portrayed as being a cheat. Teases are disconcerting to their recipients because they can readily identify themselves as at least pertaining to the minimal category/activity portrayed in the tease. As such, teases run "close to the bone" (Drew, 1987:246). It is this deviant portrayal of an otherwise feasible ascription that recipients are wont to cast off.

As mentioned previously, the presence of laughter particles and other "off-record" markers have been identified as contributing towards a recipient's reading of teases as jocular (or otherwise), and to the teasing proposal being interpretable as being non-literal. We might then expect that if teasing turns are stripped of the characteristic features that mark the frame as jocular, then recipients will find such teases to be disconcertingly ambiguous (as Keltner et al., 2001 predict). In a taunting experiment, developmental research shows that 12-14 year old children are more likely to mitigate their taunts with offrecord markers than 9-11 year old children (Keltner et al., 2001:239). The development of more sophisticated teasing techniques (i.e., with more off-record markers) approximately corresponds to reductions in the reporting of bullying (Keltner et al., 2001:239-240). But is it the case that adults find teasing that is only thinly populated with off-record markers disconcerting? And if so, how do they respond to it? There is still much to learn about what sorts of teases are likely to solicit utter po-faced rejection (Drew, 1987), and what sorts are likely to be humorously played along with by recipients. The interaction explored in this paper contributes towards advancing this understanding.

\section{The kinship system as a cognitive object}

A kinship system can be thought of as the body of communally shared knowledge about how individuals relate to each other. The Murriny Patha kinship system, like all Australian classificatory kinship systems, is an egocentric system of social organization that groups veritable non-relatives within the same kinship categories as actual relatives. Typical Australian kinship systems are built on principles that allow kinship categories to extend indefinitely to include the whole of (Aboriginal) society (Radcliffe-Brown, 1930-31). These mechanisms make it relatively easy to incorporate outsiders into the world of classificatory kin. In much of Australia, kinship systems dovetail with socio-centric systems of social organization (sections, subsections, etc.) which make the incorporation of outsiders even easier. ${ }^{3}$ Although the Murriny Patha briefly adopted subsections from their southerly Jaminjung neighbours in the early 20th century (Falkenberg, 1962; Stanner, 1936), by the beginning of the 21st century the system has all but been abandoned (Blythe, 2009; Furlan, 2005).

\footnotetext{
${ }^{3}$ Whereas kinship systems are systems of egocentric relationships (i.e., relationships are calculated from the perspective of the individual, or ego), sociocentric systems relate social categories to each other. For example, in the Warlpiri system, men of the jungurrayi subsection are cousins of men in the jupurrula subsection. See Elkin (1968 [1938]) and Berndt and Berndt (1999 [1964]) for useful introductions.
} 


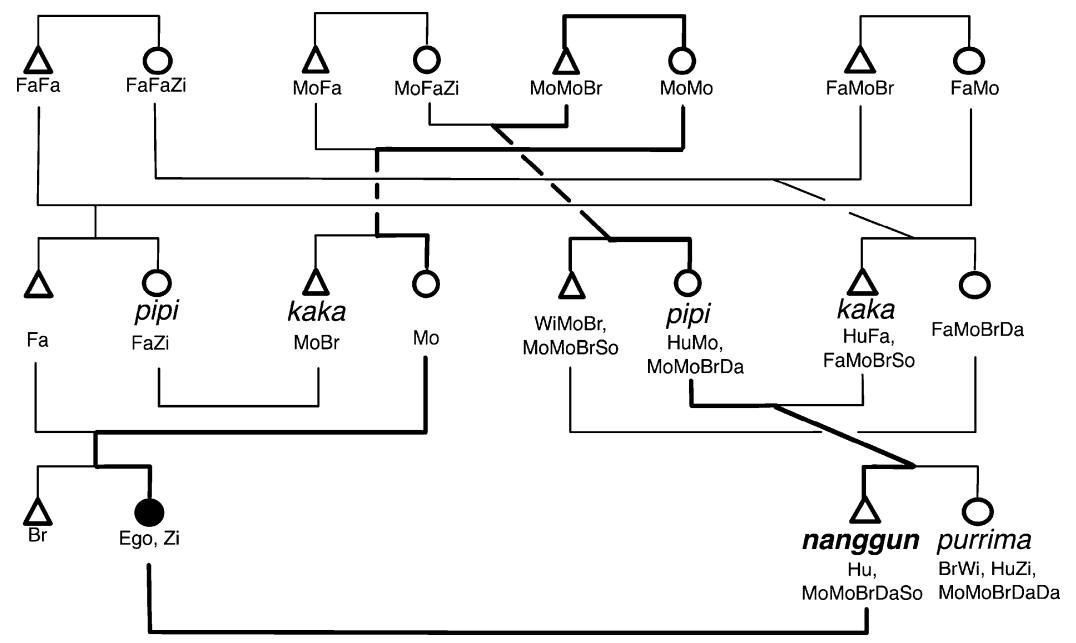

Fig. 1. The Murriny Patha kinterm nanggun from the perspective of a female ego.

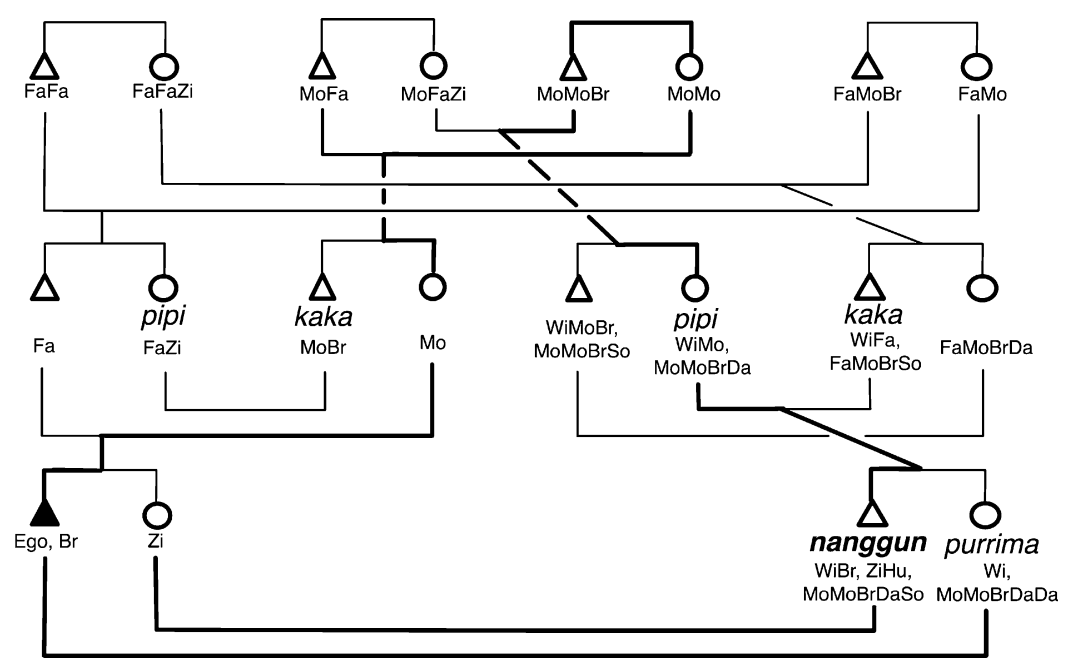

Fig. 2. The Murriny Patha kinterm nanggun from the perspective of a male ego.

In the paper we need not be concerned with the structural details of the Murriny Patha kinship system. ${ }^{4}$ We are principally concerned with a single kinterm, nanggun, which has several senses. As well as for their actual husbands (Hu), women use the word nanggun to refer to male matri-lateral second cousins (MoMoBrDaSo, see Fig. 1), ${ }^{5}$ which is the class of kin from whom husbands are preferably chosen. As such, a woman's nanggun is either her real husband or a 'potential husband'. Men however use the term nanggun to refer to both their actual brothers-in-law ( $\mathrm{WiBr}, \mathrm{ZiHu}$ ) and to potential brother's-in-law (who are also male matri-lateral second cousins, MoMoBrDaSo, see Fig. 2). The teasing encountered in this paper rides on the polysemy of this term nanggun.

In addition to the regular kinterms, there are also certain body parts that are associated with particular kin relationships. Thus a woman's children may be referred to as ngapurlu, "breast"; a person's father's sister (or the converse relation - a woman's brother's children) may be referred to as lamala, "shoulder"; and a sibling may be referred to as tharrmu, "thigh". Sensations in a particular part of the body are taken to be a sign of the corresponding relative's imminent arrival or possible misadventure. ${ }^{6}$ In the event of misfortune, relatives are regularly informed by reference to the body part (as illustrated by a consultant's invented example, given in 1). Although the forearm doesn't strictly belong to this class of kin-denoting body

\footnotetext{
${ }^{4}$ However, interested readers are directed to Stanner (1936), Falkenberg (1962), Falkenberg and Falkenberg (1981) and Blythe (2009:34-38, 2010).

${ }^{5}$ Kinterm abbreviations are as follows: $\mathrm{Br}=$ brother/brother's, $\mathrm{Ch}=$ child (son/daughter), Da = daughter/daughter's, Fa = father/father's, Hu = husband/ husband's, ma = man's, Mo = mother/mother's, So = son/son's, Wi = wife/wife's, wo = woman's, Zi = sister/sister's.

${ }^{6}$ The association of certain classes of kin with bodily tingling sensations has been reported in the Kimberley region amongst the Worrorra, Ngarinyin, Jaru, and Karajarri (Elkin, 1937), as well as in Central Australia amongst the Ngatajarra (Douglas, 1977) and the Warlpiri (Kendon, 1988).
} 


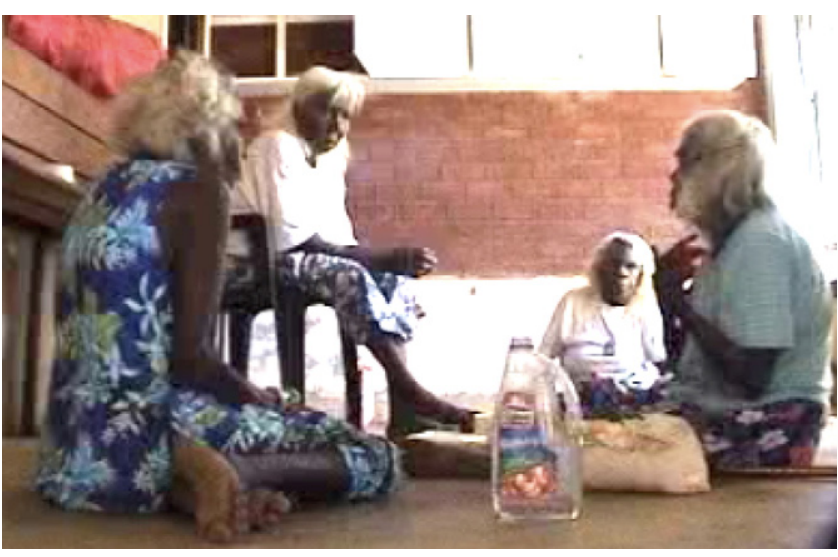

Fig. 3. From left to right: Edna, Mary, Kate and Lily.

parts, passing an object whilst holding the forearm with the other hand is one of several deferential passing practices ordinarily associated with brother's-in-law (nanggun).

1

$\begin{array}{llll}\text { ngapurlu } & \text { wiye } & \text { thandjin } & =t j i m \\ \text { breast } & \text { bad } & \text { 2sS.have.nFut } & =2 s \text { s.sit.nFut }\end{array}$

"Something bad has happened to [your] son/daughter."

[JB 2009 Fieldnotebook 2, p3]

(Literally: "You have (a) bad breast(s)".)

As well as being a lexical domain providing address and reference terms, a kinship system is a social architecture that prescribes certain behavioural rules: which persons may be married, which persons are to be avoided, which persons are to be shown special affection, etc. These rules might prescribe activities such as name-avoidance, kin-based joking and swearing, provision of food or money for people in particular relationships, as well as ritual activities relating to specific ceremonies. Some rules are so strongly prescriptive they are essentially inviolable. There is often a sound biological basis for such prescriptions (e.g., non-marriage of a biological sibling or parent). Other rules are cultural conventions that are normatively adhered to (e.g., that in Anglo-society, the father of the bride gives his daughter's hand in marriage) but from which departures are neither controversial, nor unusual. Importantly, every society has a system of kinterms and associated conventions that represent a cognitive reality for the members of that society. As such, it can be abstracted and construed of as a system. As an abstractable system, the rules are not only violable, but manipulable. They can be thought of as having a plasticity that allows them to be momentarily reconstrued and reconfigured for special purposes. Kinship systems, both in their lexical mappings and their associated behavioural rules, are cognitive resources that interlocutors can draw on for social action. Just as interlocutors can manipulate physical objects in their environment, cognitive objects such as kinship systems are available to be manipulated for interactional purposes.

In the next section we will consider three consecutive fragments from an extended teasing episode. Three of the conversationalists tease the (female) recipient of a forearm-holding passing gesture by reconstruing it as a 'husband's' display of deference to his 'wife' (thus inverting the conventional association of the gesture with 'brothers-in-law').

\section{Analyses of a forearm-holding passing-gesture}

In Fragment 2, a non-Aboriginal man called John, ${ }^{7}$ walks into the room where four elderly women are sitting and asks them for a lighter. One of the women passes him her lighter. He lights his cigarette, returns the lighter, and then leaves. John has lived in Wadeye for a year or two - long enough to have acquired at least a few words of Murriny Patha. Prior to coming to Wadeye, he worked in other Aboriginal communities in the Northern Territory of Australia. Evidently, he is quite familiar with certain particulars of Aboriginal interaction. He is, however, virtually unknown to the four elderly women.

The women, Edna, Mary, Kate and Lily (see Fig. 3) are all good friends who have known each other all their lives. They are all widows. Due to a problem with her larynx, Kate has difficulty speaking and thus relies heavily on gesture to relieve the burden on her vocal apparatus. The forearm-holding gesture that John performs as the lighter is transferred becomes the topic of conversation. In the latter fragments ( 3 and 4 ), all participants perform a variety of visible actions that include numerous replications of his forearm-holding manoeuvre. On the one hand, his passing-gesture earns him the respect and admiration of his addressees. On the other hand, it provides three of the women (Lily, Kate and Edna) with a basis to tease the other (Mary). Whether or not it was intended as such, the gesture is taken to be a physical manifestation of kinship. We begin with Fragment 2. (Readers are invited to view subtitled video clips of the ensuing fragments under discussion, see Appendix C.)

\footnotetext{
${ }^{7}$ All personal names are pseudonyms.
} 
Fragment 2 (Nanggun 20070728Jbvid01)

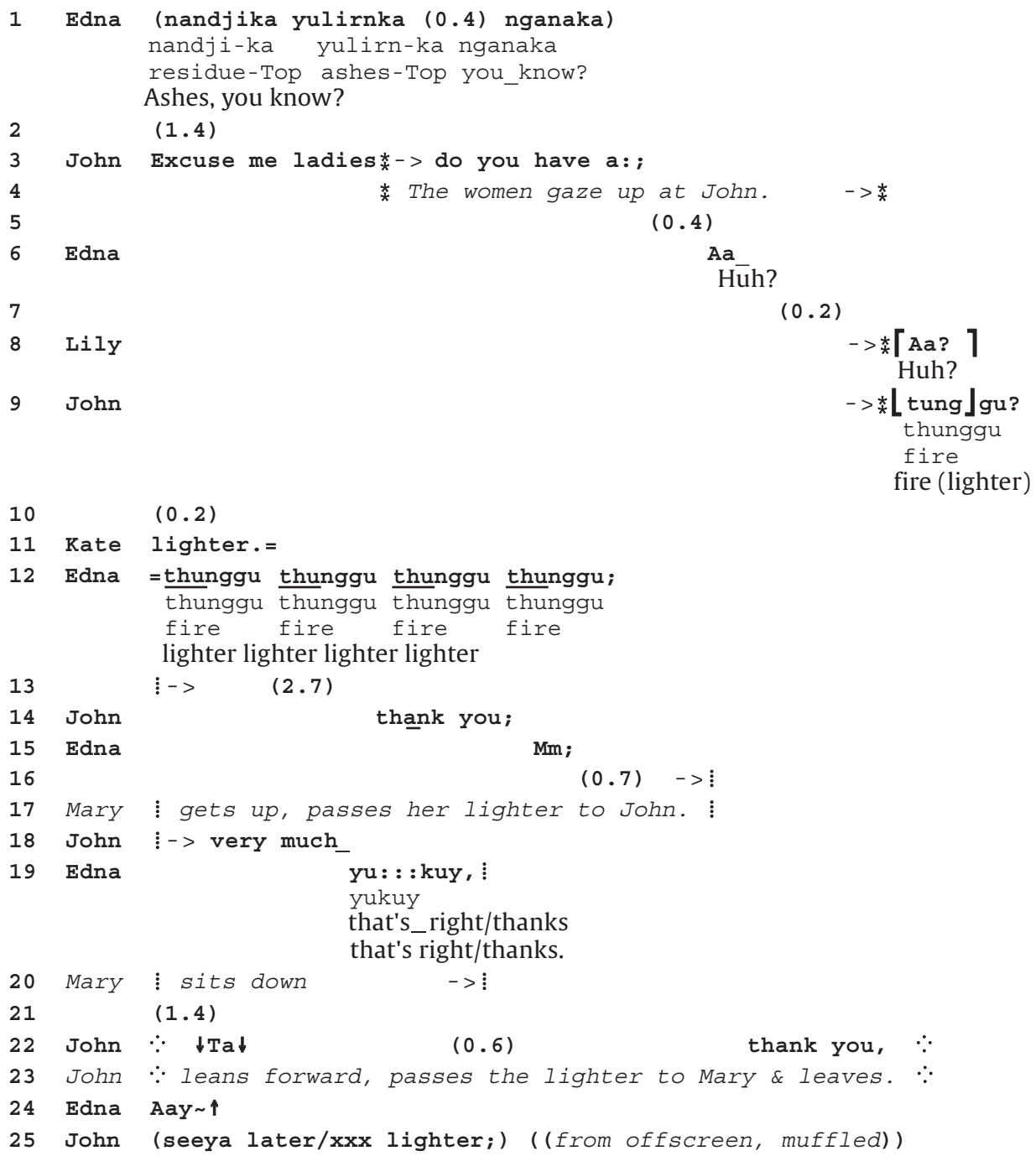

Having just appeared from the adjacent room, John, in a turn that begins at line 3 and finishes at line 9, asks the women for a light for his cigarette: "Excuse me ladies have you got a:; ...". John holds on to the slightly downward intoned indefinite article (a:;) and then pauses mid-turn until he secures their gaze. Having gained their recipiency, he continues his request by producing the Murriny Patha word for "fire" thunggu (line 9; here, slightly mispronounced as tunggu). Having been prompted by Kate and Edna to find her lighter (lines 11 and 12, respectively), Mary grants the request by standing up and passing the lighter to John. As he receives it from Mary (line 17) and returns it (line 23) (having lit his cigarette), John can be seen holding his right forearm with his left hand (see Figs. 4 and 5). These gestures are noted by Kate and Lily but not, it seems, by Edna; nor by Mary, the woman that passed him the lighter.

We now move onto Fragment 3 where Kate draws attention to John's passing-gesture. (Teasing turns have been highlighted grey.)

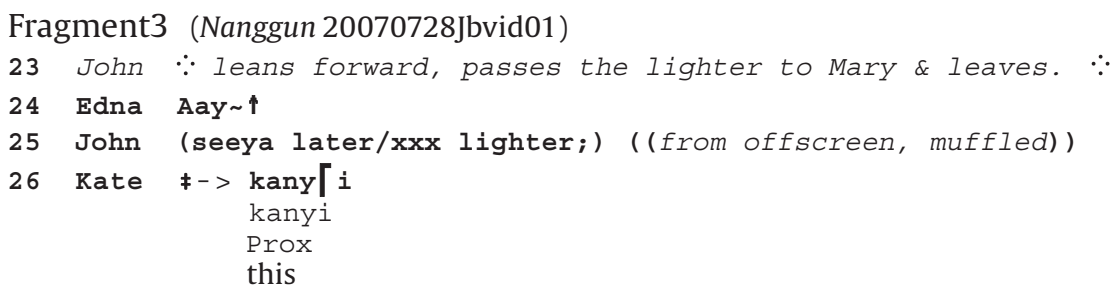




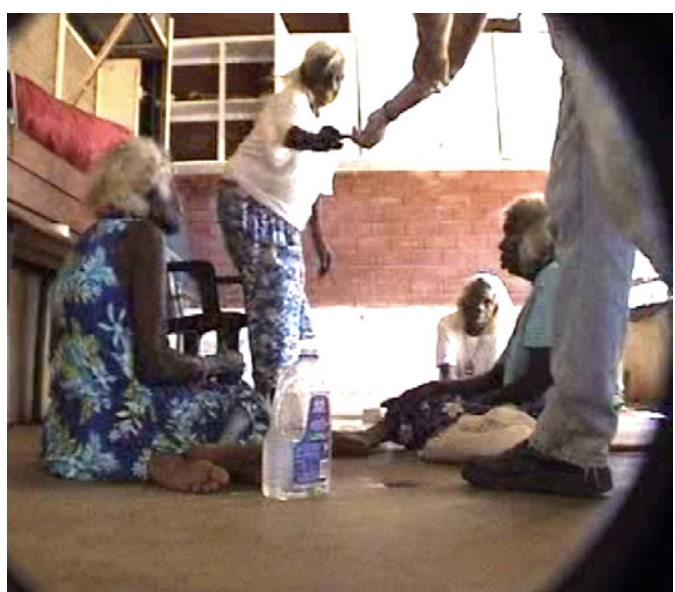

Fig. 4. Mary passes the lighter to John (line 17).

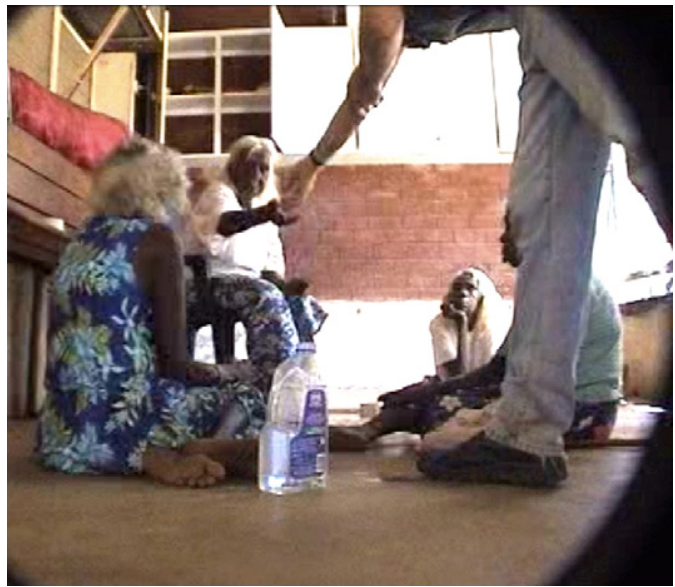

Fig. 5. John passes the lighter back to Mary (line 23).

\section{LYuwarra.}

yuwarra

yeah/thanks

Thanks.

Kate

Edna

Kate Lily

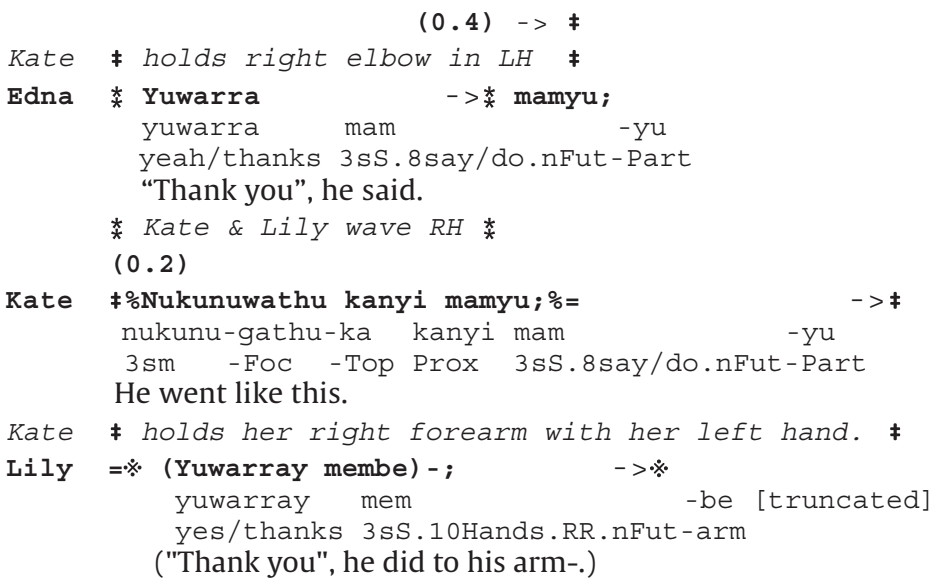


Lily $*->$ memngebe:yit. (bet, ) (0.3) * mem -nge -be -yit (bet)

3sS.10RR.nFut-3sfIO-arm-hold (??)

He held his own arm on account of her.

\begin{tabular}{|c|c|c|}
\hline $\begin{array}{l}40 \\
41\end{array}$ & $\begin{array}{l}\text { Lily } \\
\text { Edna }\end{array}$ & $\begin{aligned} * \text { holds right forearm in } L H . \quad & *,,,,,,,,,,,,,, \ldots \\
& *{ }^{\circ} \text { karra nanggunanggun; }{ }^{\circ}=* \\
& \text { karra nanggun-Redup } \\
& \text { Goodness! husband-Redup } \\
& \text { Goodness, proper husband! }\end{aligned}$ \\
\hline 42 & Mary & 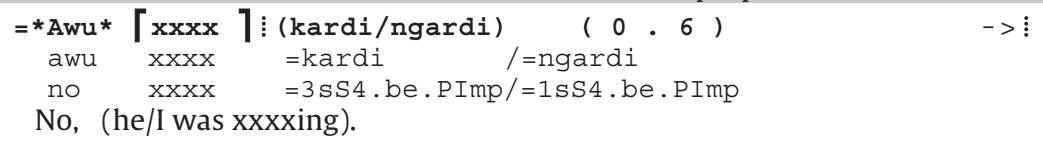 \\
\hline 43 & Lily & $\begin{array}{l}\text { Lkaka.」 } \\
\text { kaka } \\
\text { MoBr } \\
\text { [my] uncle. }\end{array}$ \\
\hline 44 & Mary & ! Smiling, shifts gaze from Edna towards Lily. \\
\hline 45 & Kate & $\begin{array}{l}\text { Nyinyi \%kardu } \uparrow \text { nanggun ninadha; } \%= \\
\text { nyinyi kardu nanggun ni -na -dha } \\
2 \mathrm{~s} \text { human husband 2sS8. say/do.PImp-3smIo-Pst } \\
\text { You were doing it [passing the lighter] to [your] husband. }\end{array}$ \\
\hline 46 & Mary & $=\neq \mathrm{mhm}$ ha ha ha ha. $\quad->\neq$ \\
\hline $\begin{array}{l}47 \\
48\end{array}$ & Kate & $\begin{array}{l}\text { * throws head back laughing } \neq \\
(1.0) \text { ((Lily, Edna \& Kate are all smiling)) }\end{array}$ \\
\hline 49 & Mary & $\begin{array}{l}\text { Ngayka mange nyinika membengga「wa; } \\
\text { ngay-ka mange nyini-ka mem -be -ngga -wa } \\
\text { ls -Top hand anaph-Top 3sS.10RR.nFut-arm-eye/face-Emph } \\
\text { I [am the reason why] he did that with his hand. }\end{array}$ \\
\hline $\begin{array}{l}50 \\
51\end{array}$ & Edna & $=x \times x\lceil x x \quad\lfloor x x x \times x x=$ \\
\hline 52 & Lily & $\begin{array}{l}\text { *\%u. membabeyit. }(0.3) \\
\text { yu mem -mba -be -yit } \\
\text { yes 3ss.10RR.nFut-2sIo-arm-hold } \\
\text { Yeah, he held his own arm on account of you. } \\
\text { *Iifts head, nods \& holds right forearm. * }\end{array}$ \\
\hline
\end{tabular}

54 Edna ${ }^{\circ}$ nanggun $*$ ninadha; ${ }^{\circ}$
nanggun ni-na-dha
husband $2 \mathrm{sS} 8$. say/do.PImp-3smIO-Pst
You were doing it to [your] husband.

\section{Kate}

$$
\begin{aligned}
& \text { Yu- u. = } \\
& \text { yu } \\
& \text { yeah }
\end{aligned}
$$

\begin{tabular}{|c|c|c|}
\hline 59 & Kate & $\begin{array}{l}\text { mamba; } \quad(0.2) \\
\text { mam } \quad-\text { mba } \\
\text { 3sS.8say/do.nFut - 3sIo } \\
\text { He did it on account of you. }\end{array}$ \\
\hline 59 & Kate & \# holds right arm with $\mathrm{LH}$. \\
\hline 60 & Lily & 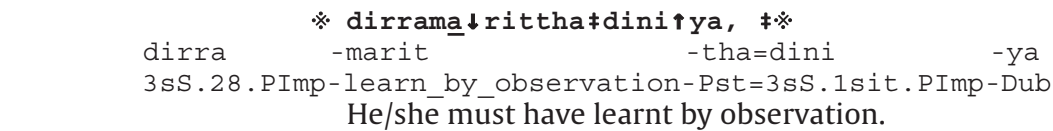 \\
\hline $\begin{array}{l}61 \\
62\end{array}$ & Lily & $*$ points to her left. $\quad->*$ \\
\hline 63 & Mary & $\begin{array}{l}\text { Ber } \begin{array}{l}\text { e. } \\
\text { bere }\end{array} \\
\text { completion } \\
\text { That's enough. } \\
\quad \vdots \text { (0.2) }\end{array}$ \\
\hline
\end{tabular}

Yea- eah.

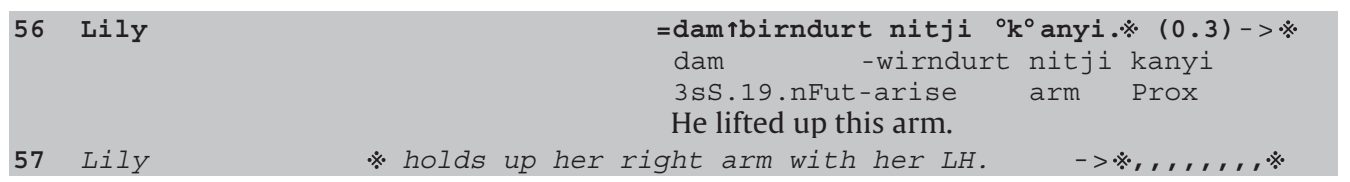


As John heads back to the adjacent room, Kate holds her elbow and begins to say "here" (kanyi, line 26 of Fragment 3 ). When she sees that she doesn't have the visual attention of her interlocutors, she abandons the turn. As John walks out, she then waves her right hand (line 31) (seemingly, as a valediction). ${ }^{8}$ As a result of the wave, she secures the gaze of Mary. She then recommences by announcing (Nukunuwathu kanyi mamyu, "he went like this", line 33) that John had made a gesture reminiscent of the one she is currently demonstrating (line 34), in which she holds her right forearm in her left hand.

Whilst gazing at Edna, Lily also demonstrates the gesture performed by John. Lily, however, encounters certain difficulties both in producing her turn at talk and in executing the gesture. Whilst raising her outstretched arms towards Edna, she begins a turn that is not completely audible (line 35). Then, whilst holding her left forearm in her right hand she self-repairs by replacing her prior - probably incomplete - utterance with a question, "Did you see his hand?" (dangammangkardu, line 37). Latched on to this question is an incomplete verb that is truncated before its meaning becomes fully apparent (memngebuye-). In a further selfrepair, she replaces the truncated verb with a similar verb memngebeyit, "he held his own arm on account of her". ${ }^{9}$ Whilst repairing this problematic verb, Lily simultaneously abandons her earlier gesture and replaces it with the mirror image of her prior one (this time her right forearm is in her left hand, line 40), thus more accurately replicating the gesture that John had produced earlier. Appreciating the significance of the gesture, Edna produces a sotto voce teasing turn (line 41) with a very compressed pitch range. The tease consists of the astonishment token karra, "goodness", followed by the reduplicated kinterm nanggunanggun, "proper husband" (woHu, MoMoBrDaSo, maWiBr, maZiHu). ${ }^{10}$ The teasing turn builds on Kate's and Lily's earlier informings (lines 33-34 and 35-40, respectively). This conjointly constructed tease lays the way open for an extended teasing episode.

The chosen kinterm nanggunanggun is produced as a highly contextualised tease that captures in a nutshell the teasability of the reproduced gesture. My consultants explained the arm-holding gesture as a proper way for a man to pass something to his nanggun; that is, to an actual brother-in-law (maWiBr, maZiHu) or to a categorial brother-in-law (MoMoBrDaSo, recall Fig. 1). Alternatives include passing through an intermediary or pushing a requested item with a stick. The passing gesture is a respectful display of deference towards the man that has bestowed his sister as a wife, or is in a category of potential wife-givers (Falkenberg and Falkenberg, 1981:36-60). Because none of John's interlocutors are male, clearly nanggun is not here being used to refer to him as a brother-in-law. However, as previously mentioned, a woman's nanggun is either her actual husband, or someone from the class of most marriageable males (MoMoBrDaSo, recall Fig. 2). Therefore, by referring to John with an intensified 'husband' term, Edna insinuates either that John is Mary's actual (and perhaps therefore secret) husband, or that he is a highly eligible prospective husband. Ordinarily this arm-holding gesture is not associated with spouses. ${ }^{11}$ In fact men have no counterpart gestures for passing objects to their purrima, "wife". Nor do women have a counterpart for passing objects to their sisters-in-laws (also purrima). Effectively, having been given demonstrations of the passing gesture, Edna takes the opportunity to tease her friend on account of John's display of respect. The tease takes advantage of nanggun having multiple senses. Because the gesture is associated with a nanggun (brother-in-law) and because nanggun is also a woman's husband, the gesture is creatively re-construed as a chivalrous act of passing from 'husband' to 'wife'.

In an utterance that is only partially audible (due to overlap with Lily's line 43), Mary, in line 42, can clearly be heard to reject the teasing proposal, Awu, "no!", though what follows this negative reaction token remains unclear. As she produces this rejection she begins to smile, very slightly, whilst turning her head away from Edna and towards Lily (see Fig. 6). Meanwhile Lily, in overlap with Mary's refutation, refers to John as her own kaka, her "uncle" (MoBr, HuFa, FaMoBrSo)(line 43). Because she calls Mary pipi or "aunt" (FaZi, HuMo, MoMoBrDa), she also here implies that John is really the 'husband' of Mary. (As in Anglosocieties, the husband of one's aunt is always one's uncle.) In line 45, Kate also teases Mary by making the "husband" association more explicit - Nyinyi kardu nanggun ninadha, "You were doing it [passing the lighter?] to [your] husband".

\footnotetext{
${ }^{8}$ At the same time Lily also waves at him (line 31 ).

9 The lexical meaning "hold" is revealed by the combination of the morpheme -yit with the reflexive "classifier subject" pronominal mem, resulting in "he/she held him/her-self" (as in B., below). In the prior verb the lexical stem itself is truncated, immediately following the morpheme occupying the incorporated body part slot of the verbal template (see A., below). In this position, the two morphemes differ in terms of a single vowel - a vowel that conveys a contrastive pair of body parts. The incorporated body part -bu "thigh" (line 37) is the trouble-source that is replaced in the repair solution by -be "arm".
}

A. mem -nge $\quad-b u \quad-y e[$ truncated] Repairable

3sSb.do.RR.nFut -3sIO -thigh -repair initiation

CSP -Obj -IBP -Lex

"on account of her, he/she did something to his/her own thigh" (line 37)

B. mem -nge -be -yit Repair Solution

3sSb.do.RR.nFut -3sIO -arm -hold

CSP -Obj -IBP -Lex

"on account of her, he/she held his/her own arm" (line 39)

${ }^{10}$ In Murriny Patha, reduplication (of nominals) denotes either plurality or intensification (Street, 1980). Because there was only a single man present, plurality may be disregarded in the present context.

11 A consultant remarked that the body part normally associated with a spouse is the mikmu, "the side of the buttocks" ("the rump"). 


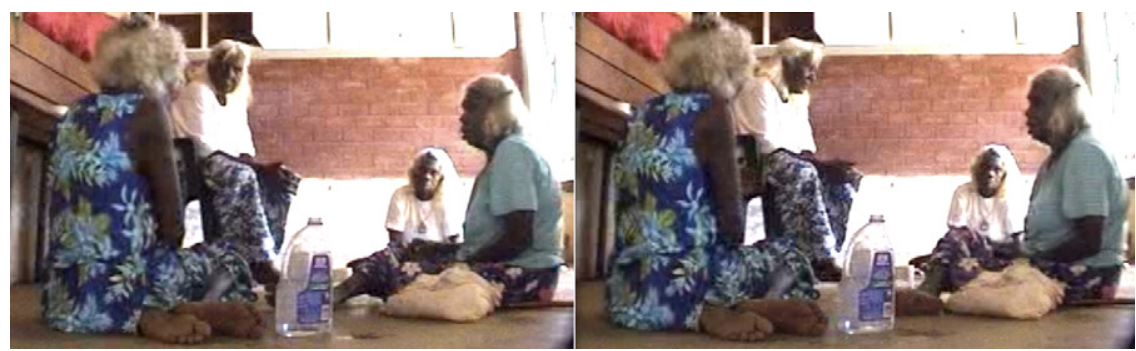

Fig. 6. Mary (second left) refutes Edna's suggestion whilst turning away from her and smiling (lines 42 and 44 ).

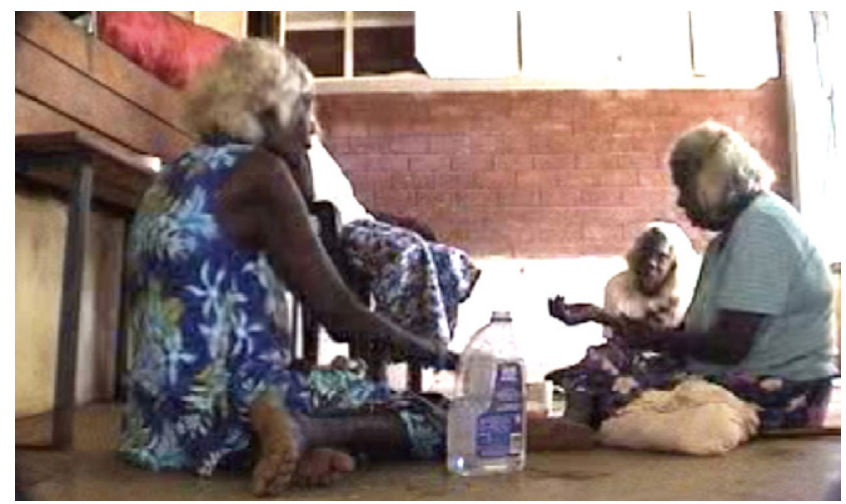

Fig. 7. Lily (far right) explains, Yu membabeyit, "Yeah, he held his own arm on account of you” (lines 52-53)

Demonstrating that she understands the nature of the teasing, Mary firstly laughs at this suggestion (line 46). Here she is joined in laughter by Kate ${ }^{12}$ and by smiles from Lily and Edna (line 48). Because they laugh with her, rather than laugh at her, this teasing appears to be affiliative (Arminen and Halonen, 2007; Glenn, 2003; Jefferson, 1972). Mary goes along with their teasing by providing non-serious support (Drew, 1987:223-225) for their account of John's gesture - Ngayka mange nyinika membenggawa, "I [am the person on whose account] he did that with his arm" (line 49). Agreeing, ${ }^{13}$ Lily again reiterates by explaining to Mary that it was on her account that he made the relevant gesture (Yu membabeyit, "Yeah, he held his own arm on account of you", line 52), whilst once again copying the gesture that he had made in the first place (see Fig. 7). In a partial repetition (nanggun ninadha, line 54) of Kate's previous explanation (line 54), Edna reiterates, sotto voce: “you was doing [it] to [your] husband".

At line 57, Lily again demonstrates the action whilst stating (dambirndurt nitji kanyi, line 56) that "he lifted up this arm" (see Fig. 8) to which Kate, whilst gazing at Mary and demonstrating the action, adds (mamba, line 58) that he performed the action on account of her (see Fig. 9). Finally, whilst pointing in the direction of the room from whence John appeared, Lily adds (dirramaritthadiniya, line 60) that he must have learnt this gesture by observing other Aboriginal people when they speak (see Fig. 9). Mary at line 63 moves to close down the teasing episode by producing a discourse marker bere, whilst slightly raising and lowering her hand (see Fig. 10). Bere, frequently translated as "finish", regularly surfaces at topical junctures, as indeed it does here. Both the discourse marker and the gesture conspire in suggesting that Mary is tiring of the teasing.

This affine-denoting forearm-holding gesture is reasonably widespread throughout the Northern Territory of Australia (something the conversationalists remark upon below). Garde (2008:241) notes that amongst Bininj Gunwok speakers of Central Arnhem Land:

[b]oth na-kurrng [WiMoBr-ZiDaHu] who are joking partners and actual na-kurrng in a constrained relationship will pass food or other objects to each other using a respectful gesture that entails holding one's own forearm - the one attached to the hand passing or receiving the object - with one's other hand. Two brothers-in-law or any pair of actual affines will do the same.

We can only speculate as to what exactly John knew about Murriny Patha passing practices. Three things, however, are clear. Firstly, although the circumstances surrounding the production of the gesture are perhaps not entirely correct, they are

\footnotetext{
${ }^{12}$ Due to her throat problem and to overlap with Mary's laughter, the microphone did not pick up Kate's laughter. She can however be clearly seen laughing in the video.

${ }^{13}$ Alternatively, the turn in lines 49-50 might be hearable as a request for confirmation of her understanding (e.g., "Am I the person on whose account he did that with his arm"?). In which case, Lily's acknowledgement token $y u$ "yes" (line 52) could be providing the requested confirmation. The turn's status as a possible request is ambiguous because Murriny Patha lacks (morpho-)syntactic resources for marking polar questions and the mid-falling final intonation contour (;) appears to be an unreliable predictor of interrogativity.
} 


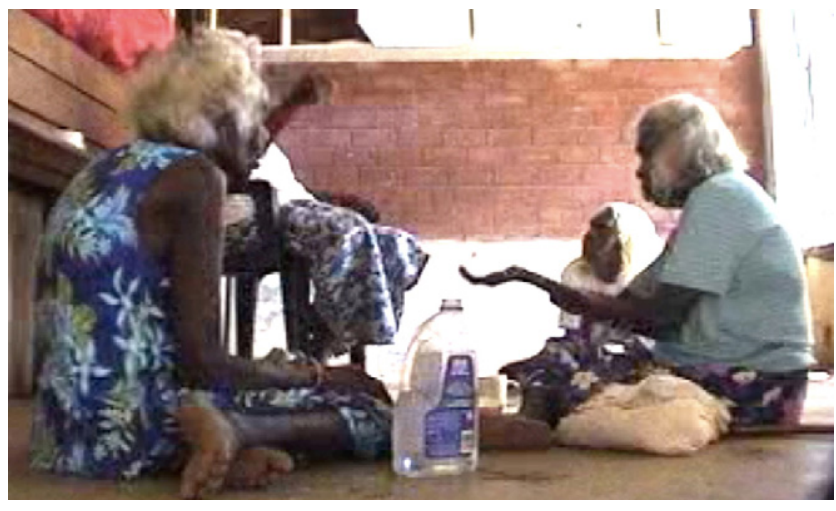

Fig. 8. Lily: dambirndurt nitji kanyi, "he lifted up this arm" (lines 56-57).

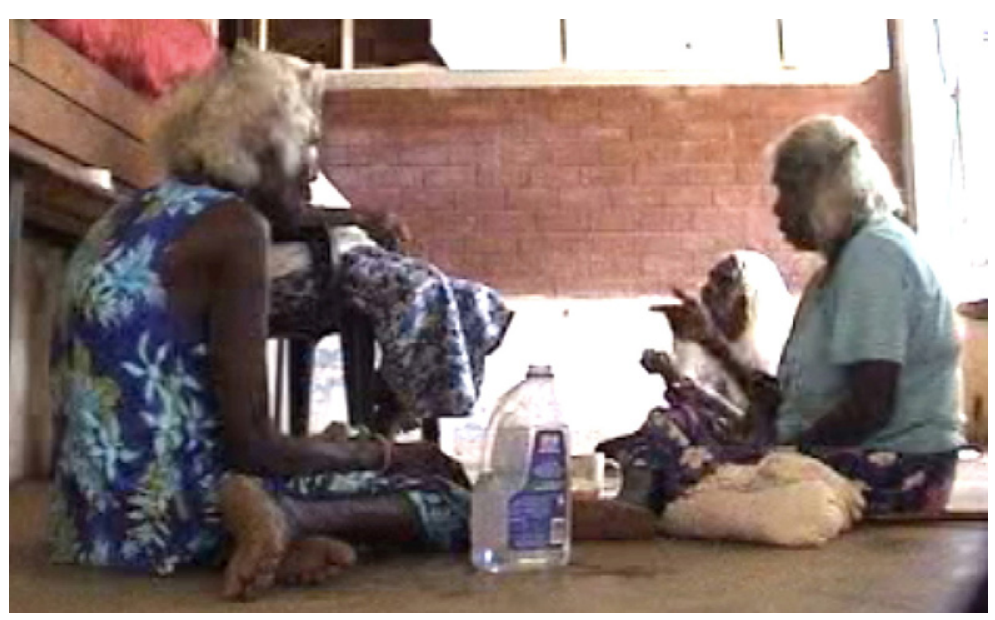

Fig. 9. Kate (second right): mamba, "he did it on account of you" (lines 58-59). Lily (far right): dirramaritthadiniya, "he/she must have learnt by observation" (lines 60-61).

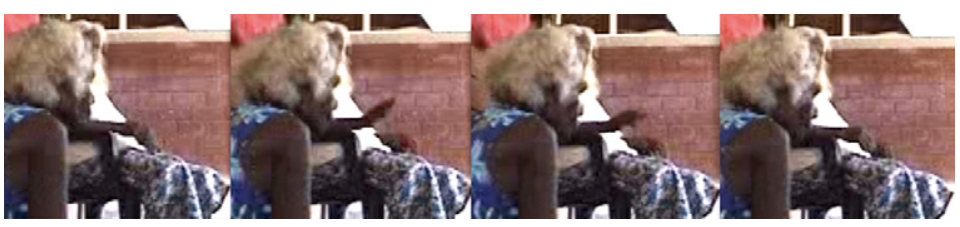

Fig. 10. Mary raises and lowers her hand whilst saying bere, "finish" ("that's enough", line 63).

certainly not completely incorrect. Because the women are senior elders of the community, a sign of respect is completely justified. With his display of respect, John has demonstrated that he is not ignorant about Aboriginal protocols. He has made a distinct impression on the women and, as we will see in the following fragment, they are clearly impressed. Secondly, the women have latched onto the gesture as being behaviour appropriate for the nanggun relationship, and have been prepared to ignore the gender misalignment in order to poke some fun at Mary. Thirdly, irrespective of whether John had previously been slotted into the kinship system, ${ }^{14}$ the women have drawn on his passing-gestures to allocate him a place, even if only as a joke. Having been allocated a position with reference to Mary, this allows subsequent calculations to be performed by reference to the other participants' relationship with Mary (e.g., Lily's calling him kaka, "uncle", in line 43). In this way the kinship system (with its lexical mappings and associated gestural conventions) becomes a cognitive tool - and indeed a flexible one - that is co-opted for the purpose of teasing.

We now move on to the final fragment of the passage.

\footnotetext{
${ }^{14}$ It is no simple matter for outsiders to be slotted into the kinship system on the basis of subsections they may have acquired elsewhere. Since the abandonment of the subsection system in Wadeye, all newcomers must be incorporated by reference to jointly known persons with whom a particular relationship has already been established.
} 
Fragment 4 (Nanggun 20070728Jbvid01)

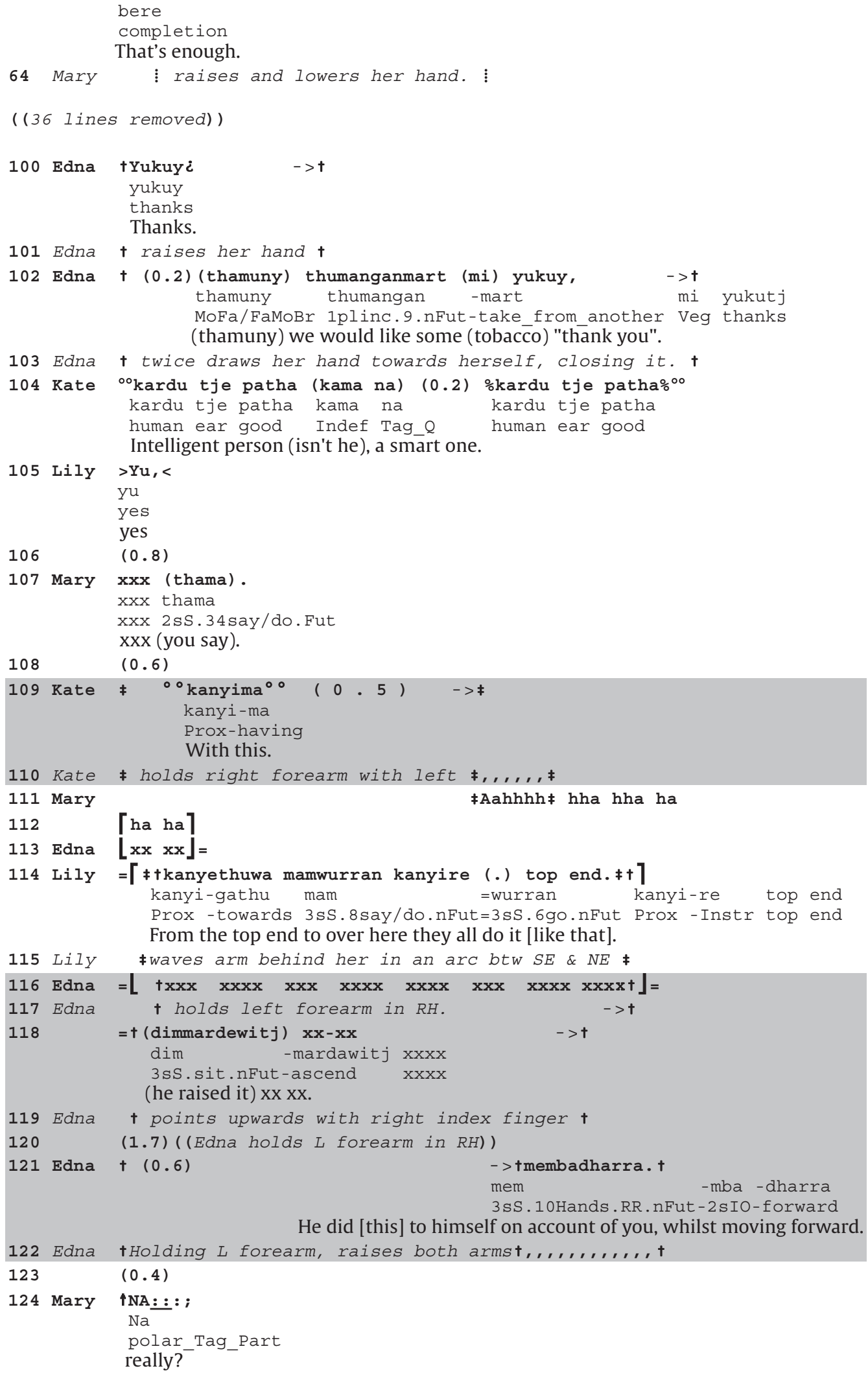




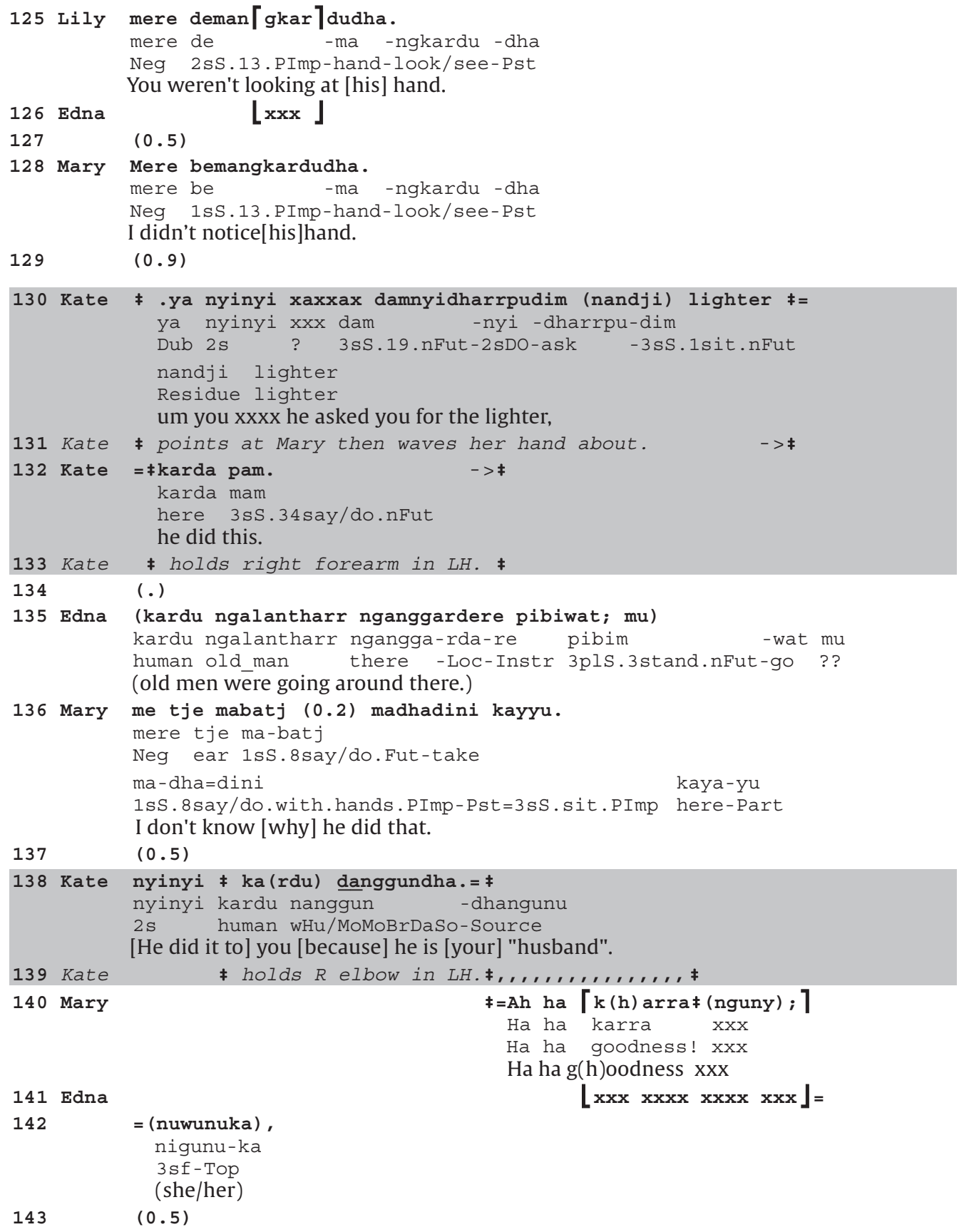

Although we do get a slight topical shift after Bere (line 63), the teasing doesn't desist altogether. Following some metapragmatic discussion of the word thank you and Murriny Patha translations thereof (lines 65-103, most of which has been removed from the transcript), Kate, in line 104, gives her appreciative assessment of John - kardu tje patha (kama na) kardu tje patha, "(He must be a) person with good ears": literally, "a smart guy"! ${ }^{15}$ Lily in line 105 agrees with this assessment - Yu, "yes". Whatever Mary mutters at line 107 is not clear. Kate, however, at line 109, takes the opportunity to elaborate on her assessment by stating kanyima, "with this", whilst once again replicating John's gesture (line 110, see Fig. 11). To the participants in this conversation, this by now familiar gesture, coupled with the deictic expression, is easily recognisable in the present context as a physical instantiation of 'spouse-hood', even if ordinarily it would not be understood as such. Mary's laughter at lines 111-112 shows that she takes the gesture and deictic expression to be yet another instance of kin-based

\footnotetext{
${ }^{15}$ In many Australian Aboriginal cultures the ear is regarded as the seat of intelligence (e.g., Evans and Wilkins, 2000).
} 


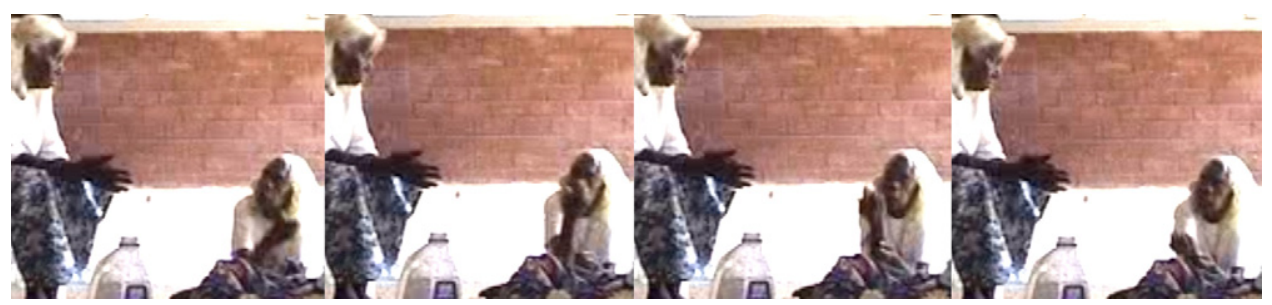

Fig. 11. Kate (right): kanyima, "with this" (lines 109-110).

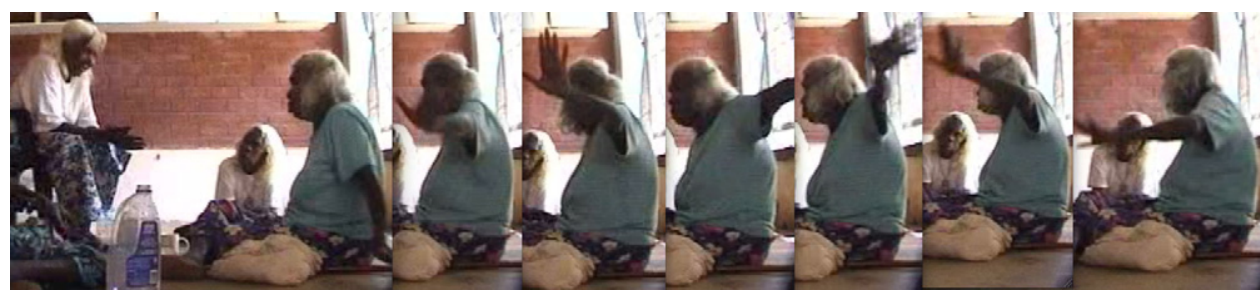

Fig. 12. Lily (right) sweeps her arm from the southeast to the northeast and back again: (kanyethuwa mamwurran kanyire (.) top end.), "from the top end to over here they all do it [like that]" (lines 114-115).

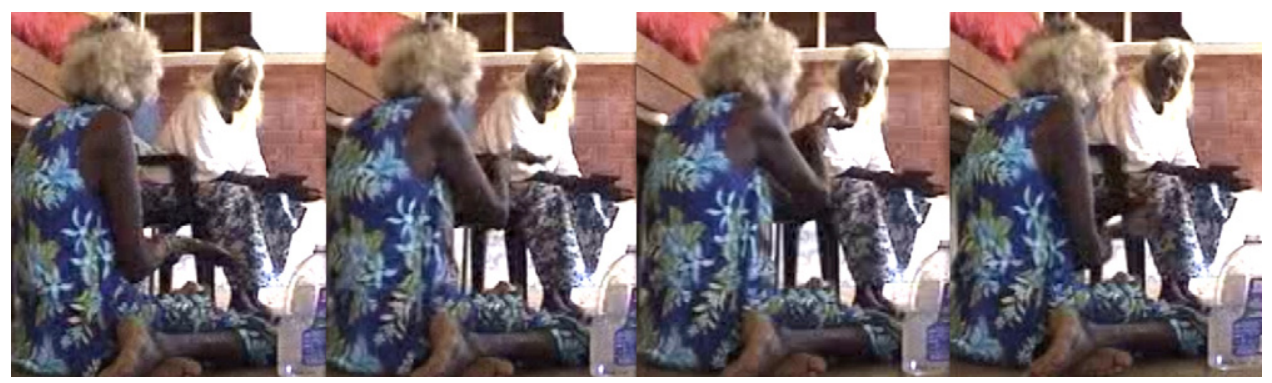

Fig. 13. Edna (left): (membadharra), "he was doing [this] whilst moving forward, on account of you" (lines 121-122).

teasing. Unlike Mary's previous bout of laughter (line 46 of Fragment 3), she is not here joined in laughter by the other women (in fact, they don't even smile).

In line 114, Lily announces that it (deferential passing whilst holding the forearm) is performed all across the 'top end'. ${ }^{16}$ As she sits facing the southwest, she makes this announcement whilst waving her arm in an arc from the southeast to the northeast and back again (line 115), effectively towards Central and Eastern Arnhem Land (see Fig. 12). The mumbled utterance that Edna produces in overlap with Lily is mostly indiscernible (line 116 is produced in overlap; line 118 is in the clear). Clearly however, as she speaks she holds her left forearm in her right hand (line 117), then points upward with her right hand (line 119); thus securing the gaze of Mary. Then, once again holding her left forearm with her right hand, ${ }^{17}$ she pauses, raises both arms towards Mary (arm-holding gesture intact, see Fig. 13) whilst producing the verb membadharra, "he was doing [this] to himself on account of you, whilst moving forward" (line 121). As such, Edna points out to Mary that John performed the 'husband'-implying gesture on account of her; or that the action was directed towards her. ${ }^{18}$ Throwing doubt on Edna's explanation, Mary seeks verification by loudly producing the interrogative particle na, "really?", "is that right?". Once Lily has pointed out that Mary wasn't actually watching (line 125), Mary explains that she didn't notice John's hand (line 128). Kate provides the requested verification by explaining (in a partially audible utterance, line 130) that when John asked her for the lighter, "he did this" (line 132); whilst once again holding her right forearm in her left hand (line 133).

Edna's line 135 is not clear enough to discern properly. Clearly though, Mary's line 136 (me tje mabatj madhadini kayyu, "I don't know why he did that") is responsive to this turn; though it is not only to this turn that it can be considered responsive. The arm-holding gesture has been performed many times and on each occasion the husband implication has been conveyed as a tease. Furthermore, several times Mary has been held to be the person on whose account the gesture was performed (lines 39, 52 and 58 of Fragment 3, and line 121 of Fragment 4). Since she has been held accountable, she is obligated to

\footnotetext{
16 The "top end" approximately equates to the tropical northern third of the Northern Territory of Australia.

17 The original gestures performed by John were not witnessed by Edna who was gazing at Mary at the time. Understandably, Edna does not here preserve the attention to handedness that Lily and Mary (both witnesses to John's gestures) have thus far displayed.

18 In Murriny Patha, the indirect object pronominals (e.g., the second person -mba, in this case) mark both beneficiary and goal (Blythe, 2009:128-129).
} 
provide some sort of account for John's action, even though she is not actually in a position to explain it. Her disclaimer at line 136, me tje mabatj madhadini kayyu, "I don't know [why] he did that", is a pseudo-explanation that absolves her of the responsibility of being accountable, thus refuting any implication of supposed secret liaisons. Effectively, as recipient of the teases, she po-facedly attempts to "put the record straight" (Drew, 1987:230).

Mary's disclaimer is stated in terms of her not knowing the reasons for John's gesture. This claim to not know makes relevant a fuller explanation from a more knowledgeable participant. Kate, whilst once again copying John's arm-holding gesture (line 139), teasingly provides the mock explanation (nyinyi kardu danggundha, line 138) that the gesture was performed because the man is her nanggun (here, "husband"). This tease succeeds in soliciting further laughter from Mary who embeds the astonishment token karra, "goodness" with laughter particles. At this point the teasing episode runs its course.

This final tease is one of the few in the episode that is directly responsive to one of Mary's just prior actions, namely her 'innocent' self-absolution for accountability (line 136). The tease is a mock-explanation in that what is actually warranted is information that advances Mary's understanding. By advancing no new information, two implications arise, depending on the construal of nanggun. The first accepts the basis for the disclaimer as being Mary having nothing to hide, and implies that the arm-holding gesture is flirtaciously indexing a potential romance; and that the ball is in Mary's court, so to speak. The teaseworthy implication here is that if she hasn't already understood this from the information provided, then she is naive. The second calls the proclaimed innocence into question (Drew, 1987). By humorously conceiving of the arm-holding gesture as normative behaviour for husband and wife couples (which of course it isn't), the implication is that the 'husband' has given the game away, so she may as well go ahead and reveal all.

\section{Discussion}

The above case-study has required us to attend to the interactional trajectory of the teasing episode, to the gestural components of the teasing, and to the recruitment of the kinship system for constructing the teases.

As mentioned previously, Drew (1987) points out that teases are typically 'seconds' that are responsive to just prior turns or just prior actions. Yet in many respects this teasing episode differs structurally from the examples that Drew provides. That the person producing the tease-inducing action immediately leaves the room has certain consequences for the trajectory of the ensuing teases. John, the producer of the teasable action, as more of a passerby than conversational participant, is not available to be teased. This leaves Mary (as co-participant in the lighter exchange and recipient of the displayed deference) to bear the brunt of the teases. Thus she generally does not perform the actions to which the teases are responding. ${ }^{19}$ John's departure occasions an extended co-constructed teasing episode consisting of multiple instances of what is more or less the same tease (with some variation in production, see below). Whilst the teases are doubtless responding to an exchange that both John and Mary participated in, they are mostly not sequential 'seconds' produced in response to just prior actions, or just prior turns at talk. Indeed, the initial tease (Edna's karra nanggunanggun, "goodness proper 'husband"', line 41) is a co-constructed effort that builds on Kate's and Lily's prior informings (lines 33-34 and 35-40).

Thus we find a disconnect between prompter of the teasing and recipient of the teasing. Whilst this is not the norm, it is not unreported (Drew, 1987). More importantly, neither party can he considered to be the subject of the teases, at least not their own right. The real subject of the teasing is the relationship between its prompter and its recipient. It is partly the questionable construal of nanggun that makes the passing-gesture tease-worthy (i.e., "Why nanggun Mary? Is there something that you haven't been telling us?"). It is the particulars of Murriny Patha kinship that make the lighter-passing a teasable item.

In this conversation, the kinship system itself becomes an interactional resource that interlocutors draw on for the special purpose of teasing. The arm-holding gesture is ordinarily associated to a subset of the class of kin that may be referred to with the term nanggun. The women take advantage of the term's polysemy in not only being used for a man's (real or classificatory) brother-in-law, but also for a woman's (real or classificatory) husband. This allows the teasers to reinterpret a gesture associated with brothers-in-law, as a gesture associated with spouses. This association of gestures with particular kinship ties, coupled with the fortuitous polysemy, provides the teasing mechanism (by switching the gesture's understood association to the non-brother-in-law senses of nanggun). This pragmatic inversion rides upon a polysemic pun.

The construal of John as a prospective (or actual) husband is facilitated by the ease with which classificatory kinship systems allow outsiders to be readily incorporated into the world of people who are relatable as kin. Thus the kinship system becomes a flexible cognitive tool that allows initial teasable construals (i.e., John as Mary's 'husband') to launch derived teasable construals (i.e., John as Lily's 'uncle', the 'husband' of her aunt).

It will be useful to consider the packaging of the various teases. There are eleven occasions (the grey-highlighted turns in the Fragments 3 and 4) in which the teasers make essentially the same point - that the man John can be considered Mary's nanggun. The eleven turns are laid out in Table 1. These turns are of three types:

- Those that explicitly name John's relationship to Mary as being of the nanggun type (A, C, E and K),

- Those that imply a nanggun relationship by replicating the forearm-holding gesture (D, F, G, H, I, J, and also K),

- Those that imply a nanggun relationship by naming a secondary relationship calculated on the premise of an understood nanggun relationship (B).

\footnotetext{
$\overline{19}$ Kate's mock-explanation tease at line 138 is an exception to this generalization. Kate's tease at lines 109-110 is also, in all likelihood, produced in response to Mary's utterance at line 106, which is indiscernible in the recording.
} 
Table 1

Turns that make the point, "he is your nanggun".

\begin{tabular}{|c|c|c|c|c|}
\hline & Teaser & Lines & Verbal component & Visual component \\
\hline A & Edna & 41 & $\begin{array}{l}{ }^{\circ} \text { karra nanggunanggun } ;^{\circ} \\
\text { goodness proper husband }\end{array}$ & \\
\hline B & Lily & 43 & $\begin{array}{l}\text { kaka. } \\
\text { uncle }\end{array}$ & \\
\hline $\mathrm{C}$ & Kate & 45 & $\begin{array}{l}\text { Nyinyi } \% \text { kardu } \uparrow \text { nanggun ninadha } ; \% \\
\text { You were doing it [passing the lighter?] to [your] husband. }\end{array}$ & \\
\hline D & Lily & $52-53$ & $\begin{array}{l}\text { Yu. membabeyit. } \\
\text { Yeah, he held his own arm on account of you. }\end{array}$ & Holds forearm \\
\hline $\mathrm{E}$ & Edna & 54 & $\begin{array}{l}{ }^{\circ} \text { nanggun ninadha } ;{ }^{\circ} \\
\text { You were doing it to [your] husband. }\end{array}$ & \\
\hline $\mathrm{F}$ & Lily & $56-57$ & $\begin{array}{l}\text { dam } \uparrow \text { birndurt nitji }{ }^{\circ} \mathbf{k}^{\circ} \text { anyi. } \\
\text { He lifted up this arm. }\end{array}$ & Holds \& raises forearm \\
\hline G & Kate & $58-59$ & $\begin{array}{l}\text { mamba; } \\
\text { He did it on account of you. }\end{array}$ & Holds arm \\
\hline $\mathrm{H}$ & Kate & $109-110$ & $\begin{array}{l}{ }^{\circ} \mathbf{k a n y i m a}{ }^{\circ \circ} \\
\text { With this. }\end{array}$ & Holds forearm \\
\hline I & Edna & $116-122$ & $\begin{array}{l}\mathbf{x x x \times x} \text { (dimmardewitj) } \mathbf{x} \mathbf{x} \mathbf{x} \text { membadharra. } \\
\mathrm{Xxx} \text { (he raised it) } \mathrm{xxx} \text { He did [this] to himself on } \\
\text { account of you, whilst moving forward. }\end{array}$ & Holds forearm, raises both arms \\
\hline $\mathrm{J}$ & Edna & $130-133$ & $\begin{array}{l}\text { ya nyinyi xaxxax damnyidharrpudim (nandji) } \\
\text { lighter karda pam. }\end{array}$ & Points, waves, holds right forearm \\
\hline K & Kate & $138-139$ & $\begin{array}{l}\text { um you xxxx he asked you for the lighter, he did this. } \\
\text { nyinyi ka (rdu) danggundha. } \\
\text { [He did it to] you [because] he is [your] "husband". }\end{array}$ & Holds elbow \\
\hline
\end{tabular}

Although all of these turns contribute towards setting up or maintaining the teasing frame, not all of them are designed as obviously being teases. Only five of these turns solicit smiles or laughter from their target (A, B, C, H and K). Not all have characteristic off-record markers that mark the frame as jocular. The first, tease $\mathrm{A}$, is clearly marked. The lexical exaggeration cued by the reduplication of the kinterm nanggun, makes it a sort of extreme case formulation (Edwards, 2000; Pomerantz, 1986). However none of these teases have drawn out vowels or unusual pitch excursions. There are absolutely no smiles or other facial cues produced mid-tease. Kate does laugh (line 47 of Fragment 3) on production of tease C, but only when the recipient Mary begins to laugh (line 46). With their expressionless faces, the three teasers, Edna, Lily and Kate are all exceedingly deadpan. Three of the teases (A, E, and $\mathrm{H}$ ) are produced sotto voce with a compressed intonation contour, a feature that has been associated with deadpan jocular irony (Attardo et al., 2003; Haugh, 2010). These deadpan markers are the most subtle of cues. The question arises, given the thinness and paucity of the off-record markers, and the rather repetitive scoring of the same point, "How is it that this teasing does not come off as boorish bullying?" A membership category analysis (Sacks, 1972a,b, 1992, vol 1:40-48; Schegloff, 2007) may provide some insight on this issue.

Recall that in Drew's (1987) terms the categories/activities invoked in a teasing proposal are usually deviant portrayals of other, less toxic categories/activities that minimally apply to the recipient or subject of the tease. In this teasing episode, one categorial domain that is activated is that of kinship. The minimal ascription that can be applied through the use of nanggun is MoMoBrDaSo (a male matri-lateral second cross-cousin), from which class men identify prospective and actual brothersin-law, and women identify prospective and actual husbands. ${ }^{20}$ Because John's relationship to Mary is otherwise unknown, this ascription (as a possible MoMoBrDaSo) is not inconceivable (and within the classificatory kinship system, is no less likely than any other conceivable relationship). However, Mary is not a man. Thus, the ascription of the deferential passing practice to the 'husband'-'wife' relationship is deviant. The intensification of which (as indexed in tease A by reduplication), makes it especially so. It is a humorous distortion of kinship practices that takes place only within the realms of fantasy. As per the formal joking relationships, this teasing indexes a potential marriage that has little likelihood of transpiring (Garde, 2008).

There are other minimal activities and categories that conceivably apply. Mary did (innocently) take place in a lighter exchange. However, the attribution of kin-based meanings to that exchange is a deviant one. The portrayal of the relationship between Mary and John (the subject of the teasing) as spousal, or potentially spousal, is a gross exaggeration of their actual relationship - namely, that of being connected merely through the exchange of a lighter. As a widow, Mary is a woman that is unencumbered by an existent marital relationship and might therefore be in a position to take on a new husband - a state of affairs that applies equally to her teasers. However, because each of the women are in their twilight years, the categorial ascription of would-be bride (or as actual wife) is both fanciful and far-fetched.

Thus, although certain minimal activities/categories can conceivably be applied, they are exceedingly tenuous, and the deviant attributions are gross in magnitude and unrealistic. As such, the teasing proposal is not one that can be taken at all

\footnotetext{
${ }^{20}$ This is the primary sense of nanggun, from which brother-in-law and husband are derived. Even if a marriage is not 'straight', the new husband or new brother-in-law is effectively assigned the classificatory MoMoBrDaSo relationship, thus becoming a nanggun.
} 
seriously. Furthermore, since any attributions relating to being 'available' for remarriage are equally applicable to the teasers, no leverage can be gained by employing such a strategy. Thus, whilst the teasing verges on the boorish, it doesn't have the teeth to bite very close to the bone.

Perhaps one indicator of the non-nasty nature of the teasing is that in line 49 (of Fragment 3 ) Mary plays along with the teases. ${ }^{21}$ Drew (1987) identifies a continuum of possible responses to teases with, at one end, the serious, entirely po-faced responses; and at the other, the cases where recipients play along with the teasing proposal. One notable feature of the teases given non-serious responses is that the degree of distortion applied in the deviant attributions is of a reasonably large order of magnitude. ${ }^{22}$ Future research might determine whether this continuum of responses is an outcome of the degree of exaggeration or distortion attributed to the minimally applicable categories/activities. Feasibly, the more outlandish the teasing proposal, or the more farcical the state of affairs, the less disconcerting (face-threatening) the teasing proposal will be for the recipients, even if they recognise themselves as conceivably portrayed in the tease. Another contributing factor might be the degree of poignancy of the minimally applicable category/activity to the recipient/subject of the tease; that is, how accurately the teaser hits the nail on the head. Thus if Mary had been actively searching for a prospective husband, then the teasing in this episode might have had a much nastier bite, and might have been met with more serious responses than it actually was. ${ }^{23}$

On the contrary, there is no hint of nastiness in these teases. Neither prompter nor target of the teases are portrayed deviantly (recall that the subject of the teasing is their relationship, not the individuals themselves). Instead, John is favourably described as being a smart guy (line 104). At the risk of speculation, perhaps the repetitive teasing reflects a hint of jealousy on the part of the teasers - if only they had been the target of such a chivalrous act. John, a younger man, enters the room and does something completely uncharacteristic for members of his own culture; thus displaying some understanding about Aboriginal protocols, as well as impeccable manners. If in Aboriginal society it is the case that asking for a light is construable as a pick-up line (as it is in Anglo- cultures), then asking in a fashion that displays deference to the bestower of the light might feasibly be construed as an incredibly smooth manoeuvre - one imminently worthy of jealousy. The teasing might thus be of the nudge-nudge, wink-wink type (i.e., "Not only is he a 'straight' marriage partner for you, he is also a gentleman"), which would make the repetitive teasing highly complimentary. Because there is nothing in the teasing suggesting that the displayed deference was unjustified, the teasing might amount to a type of flattery, which would place it far closer to the bonding end than the biting end of the teasing continuum that Boxer and Cortés-Conde (1997:276) identify.

\subsection{Concluding remarks}

These Aboriginal women have been good friends for all of their lives. Because they know each other so well, their frequent playful interactions contain humour that is both subtle and sophisticated. These very clever teases require not only good knowledge of the cultural conventions associated with particular classes of kin, but considerable mental reorganisation before they can be considered to be humorous. The teasing requires a pragmatic inversion of the senses associated with a polysemous kinterm. This is witty humour that is absolutely grounded in culturally specific common ground. Yet whilst the teasing mechanism calls on knowledge that is specific to the culture of the interactants, the bonding function of their teasing is quite probably a universal social phenomenon. It is this cohesive aspect of teasing that makes these complex and powerful actions so important for society at large.

\section{Acknowledgements}

Many thanks to Paul Drew, Rod Gardner, Nick Enfield, Olivier Le Guen and Lila San Roque for helpful comments on drafts of this paper and to the two anonymous reviewers for their very useful criticisms. I am particularly grateful to Phyllis Bunduck, Lucy Tcherna, Gertrude Nemarlak, the late Elizabeth Cumaiyi, Carmelita Perdjert and Norma Kolumboort for helping me understand their language, and particularly this conversation. Thanks also to Mark Crocombe at the Kanamkek Yile Ngala Museum and Languages Centre in Wadeye for logistical support. Funding for this research was provided by the European Research Council (StG Project 240853) and the Australian Research Council (DP0450131 and DP0878557).

\section{Appendix A. Morphological glosses}

Abbreviations used in this paper: 3 = third person, $\mathrm{Br}=$ brother/brother's, $\mathrm{Ch}=$ child (son/daughter), CSP = "classifier subject" pronominal, Da = daughter/daughter's, DO = direct object, $\mathrm{f}=$ feminine, Fa $=$ father/father's, Hu=husband/ husband's, IO = indirect object, $L H=$ left hand, Lex = lexical root, $\mathrm{m}=$ masculine, $\mathrm{ma}=\mathrm{man}$ 's, Mo $=\mathrm{mother} / \mathrm{mother}$, nFut = non-future, Obj = object pronominal (DO or IO), $R H=$ right hand, $\mathrm{RR}=$ reflexive/reciprocal, $\mathrm{s}=$ singular, $\mathrm{S}=$ subject, So $=$ son/son's, Wi = wife/wife's, wo = woman's, $\mathrm{Zi}$ = sister/sister's.

\footnotetext{
21 Recall, however, the caveat discussed under footnote 13.

22 Drew's cases included a man complaining of sickness being deviantly portrayed as having only a week to live, and a man's (apparently untrue) claim to have not slept with a woman being deviantly accounted for by his fictional homosexuality (Drew, 1987:223-225).

${ }^{23}$ The identification of these two factors suggest that the question of whether teases are to be given serious vs. jocular responses may be determined (at least in part) by the degree of distance between the deviant attributions and minimally attributable categories or activities. In order to establish whether this is so, it might be fruitful to examine cases of seemingly failed teasing; that is, where probable teases are met with hostile or irritated responses.
} 


\section{Appendix B. Key to transcription}

Symbols relating to the transcription of gesture, gaze etc.

$\because$ text $\quad->\therefore$

$\because$ gesture $\because$

*text $\quad->*$

* gesture *

‡text $->\neq$

\# gesture $\neq$

text $->$ :

! gesture !

ttext $->t$

$t$ gesture $\mathbf{t}$

thext $->$ *

* gesture *

$\neq,,, \ldots, *,,, *$

John performs visible action concurrently with above verbal utterance.

Lily performs visible action concurrently with above verbal utterance.

Kate performs visible action concurrently with above verbal utterance.

Mary performs visible action concurrently with above verbal utterance.

Edna performs visible action concurrently with above verbal utterance.

Several people perform visible actions concurrently with above verbal utterance.

Retraction of previous gesture.

Symbols relating to the transcription of speech

$\lceil, L, 1$,

$(0.9)$

(.)

-

$=$

$=$

$\mathbf{x x x} \mathbf{x x}$

(text)

( (text))

${ }^{\circ}$ text ${ }^{\circ}$

$>$ text $<$

<text>

능 text응

stress

$\downarrow, \uparrow$

$\uparrow$ text $\uparrow$

$\downarrow$ text $\downarrow$

?

$\cdot$

$i$

;

,

text
Overlapping speech.

Silence (i.e., $0.9 \mathrm{~s}$ ).

$0.1 \mathrm{~s}$ of silence.

An abrupt cut off, usually a glottal stop.

Latching (no gap or overlap between different speakers).

Where the ' $=$ ' sign occurs mid-line, this indicates the immediate continuation of the turn after a point of possible completion.

Indiscernible speech.

Difficult to discern text. Bracketing indicates either a best guess at transcription or text alleged by consultants that I believe to be dubious.

Transcriber's comments

Utterance is softer than surrounding talk.

Utterance delivered faster than surrounding speech.

Utterance delivered slower than surrounding speech.

Utterance produced with guttural or scratchy voice quality.

Stress is marked by underlining.

Colons (without underlining or adjacent underlining) indicate lengthening or drawl.

Marked shift to higher or lower pitch.

Entire utterance delivered at higher than normal pitch.

Entire utterance delivered at lower than normal pitch.

Fully rising terminal intonation.

Fully falling terminal intonation.

Mid-high rising terminal intonation.

Mid-low falling terminal intonation.

Slightly rising terminal intonation.

Completely level terminal intonation.

\section{Appendix C. Supplementary video clips}

Supplementary video clips associated with this article can be found, in the online version, at doi:10.1016/j.pragma. 2011.11.005. 


\section{References}

Alberts, J.K., 1992. An inferential/strategic explanation for the social organisation of tease. Journal of Language and Social Psychology 11, $153-177$.

Arminen, I., Halonen, M., 2007. Laughing with and at patients: the role of laughter in confrontations in addiction therapy. The Qualitative Report 13, 484513.

Attardo, S., Eisterhold, J., Hay, J., Poggi, I., 2003. Multimodal markers of irony and sarcasm. Humor 16, 243-260.

Berndt, R.M., Berndt, C.H., 1999 [1964]. The World of the First Australians: Aboriginal Traditional Life, Past and Present. Aboriginal Studies Press, Canberra. Blythe, J., 2009. Doing Referring in Murriny Patha Conversation. Department of Linguistics, University of Sydney, Sydney.

Blythe, J., 2010. Kinship structure vs. kinterm usage: a conversationally grounded re-assessment of the Murriny Patha kinship lexicon.In: Seminar Paper Presented at Australian National University, 16.3.2010.

Boulton, M., Hawker, D., 1997. Verbal bullying: the myth of "sticks and stones". In: Tattum, D., Herbert, G. (Eds.), Bullying: Home, School, and Community. David Fulton, London, pp. 53-63.

Boxer, D., Cortés-Conde, F., 1997. From bonding to biting: conversational joking and identity display. Journal of Pragmatics 27, 275-294.

Demuth, K., 1986. Prompting routines in the language socialization of Basotho children. In: Schieffelin, B.B., Ochs, E. (Eds.), Language Socialization Across Cultures. Cambridge University Press, Cambridge, pp. 51-79.

Dixon, R.M.W., 1972. The Dyirbal Language of North Queensland. Cambridge University Press, Cambridge.

Douglas, W.H., 1977. Topical Dictionary of the Western Desert Language. Warburton Ranges Dialect, Western Australia. Australian Institute of Aboriginal Studies, Canberra.

Drew, P., 1987. Po-faced receipts of teases. Linguistics 25, 219-253.

Edwards, D., 2000. Extreme case formulations: softeners, investment, and doing nonliteral. Research on Language and Social Interaction $33,347-373$.

Elkin, A.P., 1937. Notes on the psychic lives of the Australian Aborigines. Mankind: The Journal of the Anthropological Society of New South Wales 2, 49-56.

Elkin, A.P., 1968 [1938]. The Australian Aborigines: How to Understand Them, 4th ed. Angus and Robertson, Sydney.

Evans, N., Wilkins, D., 2000. In the mind's ear: the semantic extensions of perception verbs in Australian languages. Language 76, 546-592.

Falkenberg, J., 1962. Kin and Totem: Group Relations of Australian Aborigines in the Port Keats District. Oslo University Press, Oslo.

Falkenberg, A., Falkenberg, J., 1981. The Affinal Relationship System: A New Approach to Kinship and Marriage among the Australian Aborigines at Port Keats. Universitetsforlaget, Oslo.

Freedman, J., 1977. Joking, affinity and the exchange of ritual services among the Kiga of Northern Rwanda: an essay on joking relationship theory. Man 12, $154-165$.

Furlan, A., 2005. Songs of Continuity and Change: The Reproduction of Aboriginal Culture through Traditional and Popular Music. Department of Anthropology, University of Sydney, Sydney, p. 441.

Garde, M., 1996. 'Saying nothing': The Language of Joking Relationships in Aboriginal Australia, Discipline of Anthropology. Charles Darwin University, Darwin.

Garde, M., 2008. The pragmatics of rude jokes with grandad: joking relationships in Aboriginal Australia. Anthropological Forum 18, $235-253$.

Gardner, R., Mushin, I., 2010. Studies in Australian indigenous conversation. A special edition. Australian Journal of Linguistics 30.

Geyer, N., 2010. Teasing and ambivalent face in Japanes multi-party discourse. Journal of Pragmatics 42, 2120-2130.

Glenn, P., 2003. Laughter in Interaction. Cambridge University Press, Cambridge.

Goddard, C., 2006. "Lift your game Martina": Deadpan jocular irony and the ethnopragmatics of Australian English. In: Goddard, C. (Ed.), Ethnopragmatics: Understanding Discourse in Cultural Context. Mouton de Gruyter, Berlin, New York, pp. 65-97.

Handelman, D., Kapferer, B., 1972. Forms of joking activity: a comparative approach. American Anthroplogist 74, 484-517.

Harris, J., 1970. Gunkurrung: a mother-in-law language. In: Wurm, S.A., Laycock, D.C. (Eds.), Pacific Studies in Honour of Authur Capell. Pacific Linguistics, Canberra, pp. 783-789.

Haugh, M., 2010. Jocular mockery, (dis)affiliation, and face. Journal of Pragmatics 42, 2106-2119.

Haviland, J.B, 1979. Guugu Yimidhirr brother-in-law language. Language in Society 8, 365-393.

Haviland, J.B., 1986. 'Con Buenos Chiles': talk, targets and teasing in Zinacantan. Text 6, 249-282.

Heerey, A.A., Capps, L., Keltner, D., Kring, A.M., 2005. Understanding teasing: lessons from children with autism. Journal of Abnormal Child Psychology 33, $55-68$.

Hoover, J.H., Oliver, R., Hazler, R.J., 1992. Bullying: perceptions of adolescent victims in the midwestern USA. School Psychology International 13, 5-16. Jackes, M., 1969. Wikmunkan joking relationships. Mankind 7, 128-131.

Jefferson, G., 1972. Side sequences. In: Sudnow, D. (Ed.), Studies in Social Interaction. Free Press, New York, pp. 294-338.

Jefferson, G., 1979. A technique for inviting laughter and its subsequent acceptance-declination. In: Psathas, G. (Ed.), Everyday Language: Studies in Ethnomethodology. Irvington, New York, pp. 79-95.

Keltner, D., Young, R.C., Heerey, A.A., Oemig, C., Monarch, N.D., 1998. Teasing in hierarchical and intimate relations. Journal of Personality and Social Psychology 75, 1231-1247.

Keltner, D., Capps, L., Kring, A.M., Young, R.C., Heerey, A.A., 2001. Just teasing: a conceptual analysis and empirical review. Psychological Bulletin 127, 229248.

Kendon, A., 1988. Sign Languages of Aboriginal Australia: Cultural, Semiotic and Communicative Perspectives. Cambridge University Press, Cambridge.

Lyman, P., 1987. The fraternal bond as a joking relationship: a case study of the role of sexist jokes in male group bonding. In: Kimmel, M.S. (Ed.), Changing Men: New Directions in Research on Men and Masculinity. Sage, Newberry Park, pp. 148-163.

Lytra, V., 2007. Teasing in contact encounters: frames, participant positions and responses. Multilingua 26, 381-408.

Lytra, V., 2010. Constructing academic hierarchies: teasing and identity work among peers at school. Pragmatics 19, 449-466.

McGregor, W., 1989. Gooniyandi mother-in-law language: dialect, register, and/or code? In: Ammon, U. (Ed.), Status and Function of Languages and their Varieties. Mouton de Gruyter, Berlin, New York, pp. 630-656.

Miller, P., 1986. Teasing as language socialization and verbal play in a white working-class community. In: Schieffelin, B.B., Ochs, E. (Eds.), Language Socialization Across Cultures. Cambridge University Press, Cambridge, pp. 199-212.

Moore, M.M., 1992. Courtship signaling and adolescents: "girls just wanna have fun"? The Journal of Sex Research 32, 319-328.

Norrick, N.R., 2003. Conversational Joking: Humour in Everyday Talk. Indiana University Press, Bloomington, IN.

Olweus, D., 1978. Aggression in Schools: Bullies and Whipping Boys. Wiley, New York.

Olweus, D., 1993. Bullying at School: What We Know and What We Can Do. Blackwell, Cambridge, MA.

Pizzini, F., 1991. Communication hierarchies in humour: gender differences in the obstetrical/gynaecological setting. Discourse \& Society 2, 477-488.

Pomerantz, A., 1986. Extreme case formulations: a way of legitimizing claims. Human Studies 9, 219-229.

Radcliffe-Brown, A.R., 1930-31. The social organization of Australian tribes. Oceania $134-63,206-246,322-341,426-456$.

Radcliffe-Brown, A.R., 1940. On joking relationships. Africa 13, 195-210.

Radcliffe-Brown, A.R., 1949. A further note on joking relationships. Africa 19, 133-140.

Radcliffe-Brown, A.R., 1952. Structure and Function in Primitive Society. Cohen and West, London.

Rigby, P., 1968. Joking relationships, kin categories, and Clanship among the Gogo. Africa 38, 133-154.

Rumsey, A., 1982. Gun-gunma: an Aboriginal avoidance language and its social functions. In: Heath, J., Merlan, F., Rumsey, A. (Eds.), Languages of Kinship in Aboriginal Australia. University of Sydney, Sydney.

Sacks, H., 1972a. An initial investigation of the usability of conversational materials for doing sociology. In: Sudnow, D. (Ed.), Studies in Social Interaction. Free Press, New York, pp. 31-74. 
Sacks, H., 1972b. On the analysability of stories by children. In: Gumperz, J.J., Hymes, D. (Eds.), Directions in Sociolinguistics: The Ethnography of Communication. Holt, Reinhart and Winston, New York, pp. 325-345.

Sacks, H., 1992. Lectures on Conversation, vols. 1, 2. Blackwell, Oxford, Cambridge, MA.

Schegloff, E.A., 2007. A tutorial on membership categorization. Journal of Pragmatics 39, 462-482.

Schieffelin, B.B., 1986. Teasing and shaming in Kaluli children's interactions. In: Schieffelin, B.B., Ochs, E. (Eds.), Language Socialization Across Cultures. Cambridge University Press, Cambridge, pp. 165-181.

Schnurr, S., 2009. Constructing leader identities through teasing at work. Journal of Pragmatics 41, 1125-1138.

Spielmann, R.W., 1998. You're So Fat!”: Exploring Ojibwe Discourse University of Toronto Press, Toronto.

Stanner, W.E.H., 1936. Murinbata kinship and totemism. Oceania 7, 186-216.

Straehle, C.A., 1993. “Samuel?" “Yes, dear”: teasing in conversational raport. In: Tannen, D. (Ed.), Framing in Discourse. Oxford University Press, New York, Oxford, pp. 210-230.

Street, C.S., 1980. Reduplication in Murinbata, Papers in Australian Linguistics, No. 12, 58 ed. Pacific Linguistics, Canberra, pp. 1-21.

Thompson, D.F., 1935. The joking relationship and organized obscenity in North Queensland. American Anthropologist 37, 460-490.

Thorne, B., 1993. Gender Play: Girls and Boys in School. Rutgers University Press, New Brunswick, NJ.

Voss, L.S., 1997. Teasing, disputing, and playing: cross-gender interactions and space utilization among first and third graders. Gender and Society 11 .

Joe Blythe is an interactional linguist in the Language and Cognition group at the Max Planck Institute for Psycholinguistics. His field experience is with Australian Aboriginal languages. He is currently working on face-to-face interactions conducted in the Murriny Patha language. His interests include referential processes, preference organization, requests, repair, prosody, kinship and kin-based morphosyntax, and the evolution of language. 